
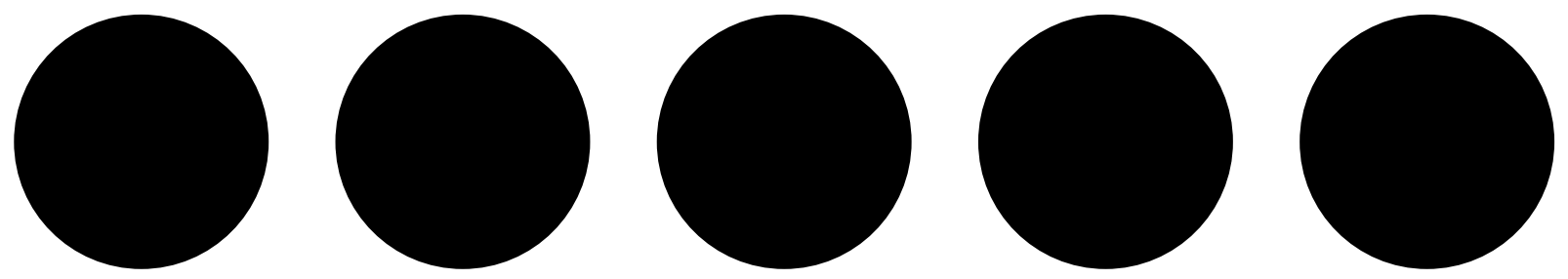

\title{
Alimentation saine issue d'une production alimentaire durable
}




\section{Table des matières}

Résumé

Portée et structure du Programme national

de recherche 69 «Alimentation saine et

production alimentaire durable

$\bullet \bullet \circ 00$ Encourager une alimentation saine et durable

Un système alimentaire suisse plus durable

Analyse des politiques suisses ayant Analyse des politiques suisses ayant
une incidence sur le système alimentaire

Conclusions et recommandation

Glossaire

Bibliographie

Annexes

FN $\underset{\text { Fonos Natio }}{\mathbf{N F}}$

Alimentation saine et
production alimentaire durable
Programme national de recherche PNR 69 
Les interactions entre l'alimentation, la santé et l'environnement ont été largement explorées dans le cadre du Programme national de recherche 69 (PNR 69), dans le
contexte du changement climatique et à l'heure où les régimes alimentaires sont d'une importance croissante pour la santé humaine. La qualification et la quantification de ces interactions presentent encore des lacunes, mais les connaissances actuellement disponibles suffisent pour que les decideurs puissent établir un sys-

La population mondiale devrait atteindre les 10 milliards de personnes d'ici à 2050. Assurer l'approvisionnement alimentaire d'une telle population de façon durable reteurs devraient doubler leur production d'aliments, et ce malgré l'impact du changement climatique sur des ressources essentielles telles que leau, le sol et lénergie. Dans ce contexte, la Suisse se caracterise par ses surfaces agricoles limitees. environ un quart du territoire pine La production est restreinte: de ce fait, une grande partie $(50 \%)$ des aliments doit être importée en Suisse.

Une autre caractéristique est la grande prévalence de maladies chroniques (principalement les maladies cardiovasculaires et le cancer), dont beaucoup seraien liees à l'alimentation. Les stratégies de santé publique tendent à optimiser lapport alimentaire en fonction des connaissances biomedicales. En ce sens, on tend de plus en plus à considerer le systeme alimentaire no comme un fournisseur de santé.

Le PNR 69 propose une série d'analyses et de recommandations basées sur les résultats de plus de vingt groupes de recherche. La principale recommandation est d'elaborer une strategie portant sur le système alimentaire suisse, c'est-à-dire une strategie garantissant une allmentation saine et durable pour lensemble de la population. L'élaboration de cette stratégie pour le syscoordonné de la part des domaines de la santé publique, de l'agriculture, de l'industrie agroalimentaire et de l'environnement. Selon une analyse réalisée dans le cadre du PNR 69, les politiques en matière de sécurité alimentaire et de santé publique poursuivent des objectifs fondamentalement coherents. Le domaine des politiques agricoles, établ depuis plus longtemps, presente quant à lui divers intérêts contradictoires.
Une stratégie portant sur le système alimentaire suisse placerait aussi l'alimentation dans le contexte de la trandu fait que deux tiers de l'empreinte environnementale suisse ont actuellement lieu à l'étranger. La stratégie alimentaire nationale ferait ainsi partie integrante de la stratégie globale visant à gerer le changement climatique.

Un objectif important de la stratégie alimentaire sera de définir quels types de régimes alimentaires sont souquestion est complexe, car l'alimentation humaine est à la fois une conséquence et un déterminant des changements climatiques.

Cette stratégie sera aussi destinée à encourager la recherche académique sur les interactions entre l'alimentation, la sante et lenvironnement. Le PNR 69 a montre que malgre la grande qualité de la recherche seuls quelques groupes travaillent sur les aspects transversaux du systeme alimentaire. En outre, de nouvelles voies de coopération entre le secteur privé et la recherche académique sont nécessaires.

Une des tendances émergentes qui a été identifiée consiste à renforcer les partenariats entre producteurs et consommateurs. Le PNR 69 recommande egalemen la mise en place de mesures visant à augmenter linfluence des consommateurs sur les decisions liées a recours des organisations de protection des consoit de teurs et de donner aux consommateurs le droit de s'associer à des plaintes collectives.

Modéliser le système alimentaire actuel et futur peut tement à comprendre son fonctionnement. Selon la litterature disponible, ainsi que les modélisations produites dans le cadre du PNR 69, reduir la consommation de viande est probablement le plus important determinant lie à lalimentation dans la transiplus duran systeme almentaire à la fors plus sain et possible d'atteindre une alimentation plus saine et un système alimentaire plus durable par l'entremise d'actions individuelles: l'amélioration de l'état de santé de la population, la protection de l'environnement et la gestion de la production alimentaire doivent être intégrées dan un cadre systemique, puis dans une stratégie commune. 
Les différents projets sélectionnés et financés par le PNR 69 ont formulé des recommandations spécifiques. Pour favoriser l'alimentation saine et durable, les organismes population suisse sur les bienfaits des régimes comportant davantage de fruits et légumes et moins de viande. Le PNR 69 montre que souvent, les regimes alimentaires prevenant les maladies chroniques et degeneneratives sont aussi benenques ques pour les interventions sur les prix devraient être développées pour encourager les choix des consommateurs. Par ailleurs, le lieu de travail représente un environnement approprié pour promouvoir l'alimentation saine. Un nouvel outil a été développé pour surveiller l'apport calorique et aider à la perte de poids. Les maladies carentielles sont un sujet classique de la médecine nutritionnelle. De nouvelles approches ont ete proposees, par exemples au travers du developpement de lisation aux carences en vitamine D durent la grossibse.

Differentes approches devront être explorés pour améliorer la durabilité du système alimentaire suisse. Il s'agit notamment d'accroître la performance environnementale des exploitations laitières, en réduisant notamment leurs émissions de particules, de protéger l'environnement des animaux, ou de limiter la pollution des sols par les metaux. Les nouvelles informations visant à optimiser la rotation des cultures ou à eviter les infections fongiques peuvent aussi contribuer à ameliorer lefficaportant pour accroitre l'efficacité du système alimentaire est la réduction des pertes et du gaspillage alimentaires. De nombreux projets ont développé des idées et outils novateurs dans ce domaine.

Comme pour les autres Programmes nationaux de recherche, les thematiques couvertes par le PNR 69 on été definies par le Conseil federal. Le programme a éte géré par le Fonds national suisse de la recherche scientifique. La caracteristique principale de ces programmes et futures d'importance nationale. 
Portée et structure du Programme national de recherche 69

«Alimentation saine et production alimentaire durable »
Depuis 2013, 26 groupes de recherche financés par le Programme national de recherche "Alimentation saine et production alimentaire durable» [PNR 69] ont réalisé des études sur l'alimentation saine issue d'une production alimentaire durable en Suisse. Ce chapitre décrit certaines caractéristiques du système alimentaire suisse, ainsi que les défis auxquels il est confronté. Il présente
En Suisse, 8,4 millions de consommatrices et consommateurs se trouvent au bout de la chaîne d'approvisionnement alimentaire ${ }^{1}$. Les connaissances et les politiques actuelles tendent à remplacer la notion de "consommateurs" par celle de "consommateurs sains", ce qu'illustrent certains changements de priorites politiques, de la disponibilite des aliments (et des calories) vers des pratiques de consommation alimentaire saines ${ }^{2}$. Cette est considéré non seulement comme un foumentaire d'aliments, mais aussi comme un fournisseur de santé En raison de l'impact notable du système alimentaire sur l'environnement (avec le changement climatique, le stress hydrique et la diminution de la biodiversité $)^{3}$, l'alimentation est aussi considerée comme un facteur déterminant de la durabilité environnementale.

En 2016, la part de la consommation alimentaire (en termes denergie utilisable) couverte par la production alimentaires importées en Suisse s'élevait à 12 milliards de francs (CHF). Les importations sont une conséquence des limites géographiques et naturelles de l'agriculture suisse, ainsi que de la mondialisation du commerce alimentaire. Elles contribuent à la diversité des régimes alimentaires tout au long de l'année. Cependant, comme la moitie de ses allments proviennent de lexterieur du pays, la Sulsse dépend beaucoup du marche allmentai

En 2018, les dépenses de la Confédération pour soutenir la production alimentaire représentaient $5,2 \%$ du nir la production alimentaire representaient $5,2 \%$ du l'administration, l'exécution et le contrôle des dépenses, l'amélioration des bases de production, la production et les ventes, ainsi que les paiements directs ${ }^{4}$. L'objectif de ce soutien est de "donner à l'agriculture les moyens de contribuer, par une production durable et axée sur le marche, a la securite de lapprovisionnement de la population, à la conservation des ressources naturelles, a sée du territoire et au bien-être des anima decentralisee du territoire et au bien-etre des animaux". Le système de tarifs et de financements publics accordés par l'Etat fédéral. 


\section{ourquoi s'en préoccuper}

La population mondiale (environ 7,7 milliards de personnes a ce jour) est en augmentation et cette croissance durera au moins jusqu'en 2050. Assurer l'ap-
provisionnement alimentaire de dix milliards d'êtres humains de façon durable est un défi de taille ${ }^{5}$. Les agricultrices et agriculteurs devraient doubler leur production alimentaire dici 2050, dans un contexte où de nombreuses regions risquent d'etre frappées par les consequences du changement climatique. Ces dernières sources énergétiques, toutes importantes pour la pro-

Bien que la quantification des interactions entre le changement climatique, l'état de santé de la population et lalimentation soit encore lacunaire, les connaissances scientifiques disponibles à ce jour suffisen pour que les decideurs politiques agissent aujourd'hu

La famine a disparu de l'Europe occidentale il y a 70 ans (depuis la fin de la Seconde Guerre mondiale). Mais au niveau mondial, près d'un milliard de personnes se trouvent en situation d'insécurité alimentaire

Trois problèmes se profilent: l'un est lié à la quantité de denrees alimentaires, lautre à la qualité nutritionnelle des aliments, et le dernier a la durabilité. Augmente la production alimentaire est une reponse evidente a augmentation aurait des impacts environnementaux substantiels, tels que la diminution de la biodiversite, la raréfaction de l'eau douce, la dégradation des sols, le changement climatique et la sur-fertilisation. Des solutions innovantes sont donc nécessaires pour nourrir la population de demain sans causer un impact environnemental démesuré

De solides arguments plaident en faveur d'une diminution de la consommation d'aliments d'origine animale de la consommation est limpact environnemental èeve est la préoccupation croissante concernant le bien-être des animaux en conditions d'élevage industriel. Enfin la réduction de la consommation de viande rouge et, en particulier, de viande transformée, pourrait aussi être bénéfique pour la santé 9 .

La production de nouveaux aliments sources de protéines, comme certains insectes, est en train de se développer. Les aliments qui permettent de substituer la présents sur le marché - étalit par exmple du tofu du tempeh, du seitan
Une autre réponse à la demande alimentaire accrue est de limiter les pertes et le gaspillage. Environ 33\% des aliments consommables sont perdus ou gaspillés à l'échelle tonnes d'aliments gaspillés chaque année ${ }^{11}$. Des outils appropriès, alliant incitations et pénalites, sont nécessaires pour minimiser ces pertes et gaspillages.

En ce qui concerne la qualité de l'alimentation, la diversité des régimes alimentaires est le facteur le plus mentation en Europe occidentale $e^{12}$. Cette diversité explique probablement une bonne partie de l'amélioration historique de l'état de santé en Europe occidentale. Mais cette diversité a un coût environnemental, car elle dépend notamment des importations et/ou d'une production non-saisonnière.

La supplémentation en vitamines et autres micronutriments a suscité de grandes attentes au cours de la ont permis de lier des maladies à des agents protecteurs ou toxiques spécifiques. En corrigeant ces anomalies, ces maladies ont pu être contrôlées ou éliminées (par exemple, l'iode contre le goître endémique, la vitamin B3 contre la pellagre, la vitamine C contre le scorbut etc.). Toutefois, les interactions entre alimentation et sante sont en general beaucoup plus complexes: seul un nombre tres restreint de pathologies sont liees causalement et directement à un seul produit sper

La production alimentaire est considérée dans un contexte toujours plus large: l'impact environnementa du système alimentaire a gagné en importance et les et la diminution de la biodiversité ont mis la production alimentaire sur le devant de la scene. La production alimentaire est à la fois une conséquence et une cause des problèmes environnementaux. Elle contribue au changement climatique (en augmentant les surfaces cultivables de méthane via l'élevage animal, par exemple), mais même temps, l'évolution du climat a un impact sur le volume et la nature de la production alimentaire (par exemple, en reduisant la biodiversite).

Compte tenu des pressions croissantes liees au changement climatique et aux divers parametres écologiques, de vives inquietudes dans l'opinion publique.

Le Programme national de recherche (PNR) 69 a été tifier quelques-unes des solutions visant à créer un système alimentaire durable pour une alimentation saine en Suisse. 
PNR 69: trois questions clés Les Programmes nationaux de recherche (PNR) sont un
moyen d'aborder de nouvelles questions et d'explorer les potentielles réponses à des problématiques socio-économiques d'importance nationale. Les PNR doivent génére des connaissances scientifiques visant à repondre aux problemes les plus urgents en Suisse. Le Conseil fédéra definit les themes. Les programmes sont conduits par le Fonds national suisse de la recherche scientifique (FNS).

Une nouvelle série de PNR est lancée périodiquement, avec un budget allant de 15 à 30 millions $C$. Leur la recherche). En général, 20 à 50 projets coordonnés sont financés sur une période de recherche de trois à quatre ans.

Les PNR se caractérisent par leurs approches de résolution de problèmes, l'inter- et la transdisciplinarité, la coordination de projets individuels et de groupes en vue mise en œuvre des résultats et le dialogue avec les publics cibles.

Le PNR 69 a été lancé en mars 2011, sur mandat du Conseil fédéral au FNS. Au cours de l'été 2011, des expertes et experts internationaux ad hoc ont été invités à définir le contenu du programme. Ils se sont bases sur les propositions de programme soumises au Secretariat dEtat à la formation, à la recherche et à linnovation (SEFRI) par les scientifiques et les offices féderaux. Le Département fédéral de l'intérieur en mars 2012 .

De février à avril 2012, les membres du comité de direction ont été élus et l'appel à projets a été publié.

Le programme fait l'objet de coopérations entre le PNR 69 et la Commission pour la technologie et linnovation (CTI) - desormais remplacée par l'Agence suisse pour l'encouragement de linnovation Innosuisse - et la Joint Programming Init

Au niveau de la recherche, l'objectif du programme était de répondre à trois questions clés:

\section{Comment encourager la population établie en Suisse} à manger sainement ?

Comment mettre à disposition des produits sains et sûrs à des prix abordables ?

Comment gérer la production, la transformation et la distribution d'aliments de manière efficace avec moins d'impact possible sur l'environnement?
Les chapitres 2 et 3 , fondés sur les résultats des projets de recherche du PNR 69, apportent des réponses à ces questions. Le chapitre 4 offre ensuite une analyse du paysage politique suisse dans les domaines de l'agriculture, de la securite alimentaire et de la sante publique. Le dernier chapitre de ce rapport de synthèse contient peuvent être tirées du PNR 69. 


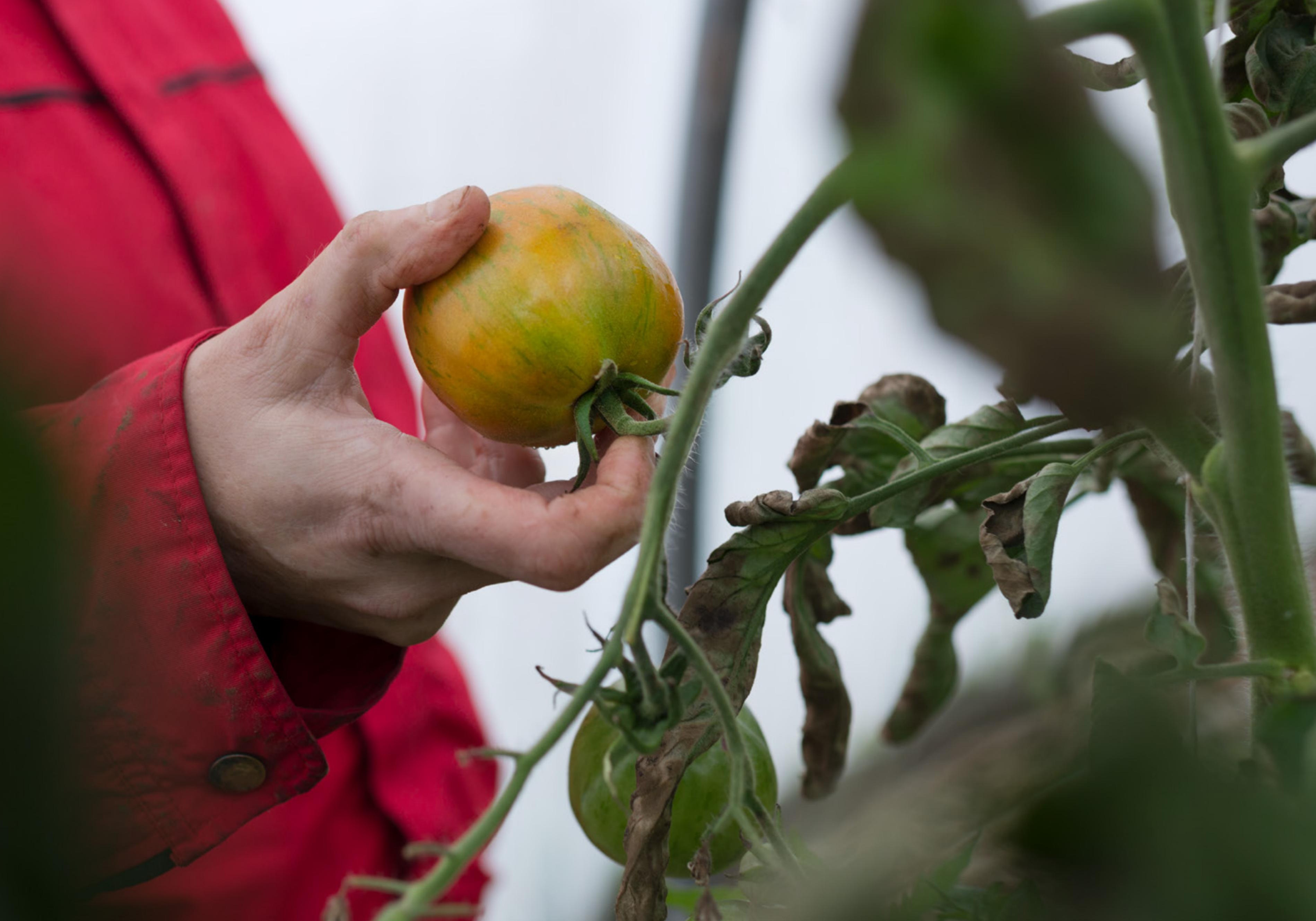


Dans le cadre du Programme national de recherche 69 , des groupes de recherche ont observé de près les habitudes alimentaires de la population suisse. Un régime alimentaire sain et durable d'origine animale, tels que la viande rouge et transformée. Cette section propose une synthèse des résultats des projets du
PNR 69 sur les thèmes de la santé et de I'alimentation durable.

\section{Encourager}

\section{une alimentation \\ saine et durable}

\section{Contexte}

Si l'on compare l'alimentation actuelle en Suisse avec l'alimentation idéale de nombreuses personnes mangent de manière malsaine et/ou non durable. Ceci, bien que le niveau moyen de connaissances en matière de sante soit élevé: la majeure partie de la population suisse arrive à distinguer les aliment sains des aliments malsains, ou une alimentation durable d'une alimentation non durable. De telles divergences sont courantes dans les domaines de l'environnement ou de la sante publique. les consommatrices et consommateurs lieu de reconnatre que l'impact du savoir sur les habitudes alimentaires limité. Afin de comprendre les divergences entre connaissances et choix nous devons tenir compte des facteurs qui influencent les habitudes alimentaires des consommateurs.

Le choix des individus de manger de manière malsaine et/ou non durable repose sur plusieurs motifs. Certains manquent de temps pour preparer les repas, d'autres se tournent vers les aliments les moins chers. Les fringales, le plaisir et les récompenses jouent egalement un röle important. Les personnes développement de maladies comme le diabète, les maladies cardiovasculaires ou le cancer. En Suisse, les coûts directs et indirects d'une alimentation désequilibrée sur la santé ont triplé entre 2002 et 2012, allant jusqu'à huit milliards de francs par année ${ }^{13}$.

En outre, les habitudes alimentaires ont un impact direct sur l'environnement. Le PNR 69 a démontré qu'en Suisse, les produits d'origine animale sont responsables d'au moins $40 \%$ de l'impact environnemental de la consommatio
alimentairea.

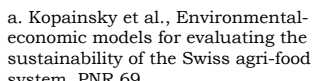

Plus de fruits et de
légumes, moins de viande

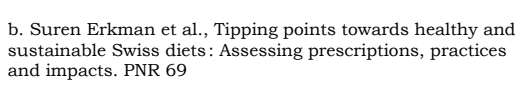

b. Ibid.

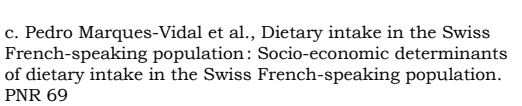
Le projet "Vers des régimes sains et durables en
Suisse " a été réalisé dans le cadre du PNR 69. Il a examiné les habitudes alimentaires de la population suisse.

En moyenne, les hommes mangent davantage de viande que les femmes. Par ailleurs, les personnes habitant en Suisse romande et au Tessin ont tendance à mange moins sainement que les habitantes et habitants de la

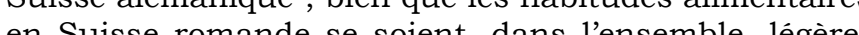
ment améliorées entre 1993 et $2014^{\circ}$.

L'une des caractéristiques de la population suisse est que le décalage entre les habitudes alimentaires des personnes appartenant à différents groupes socio-économiques est moins important que dans d'autres pays. Globalement, les habitantes et habitants suisses devraient manger davantage de fruits, de legumes, de cèréales complètes, de fruits à coque et de légumineuses, 


\section{Les coûts d'une alimentation déséquilibrée}

En Suisse, les coûts directs et indirects
d'une alimentation déséquilibrée sur la sant ont triplé entre 2002 et 2012.

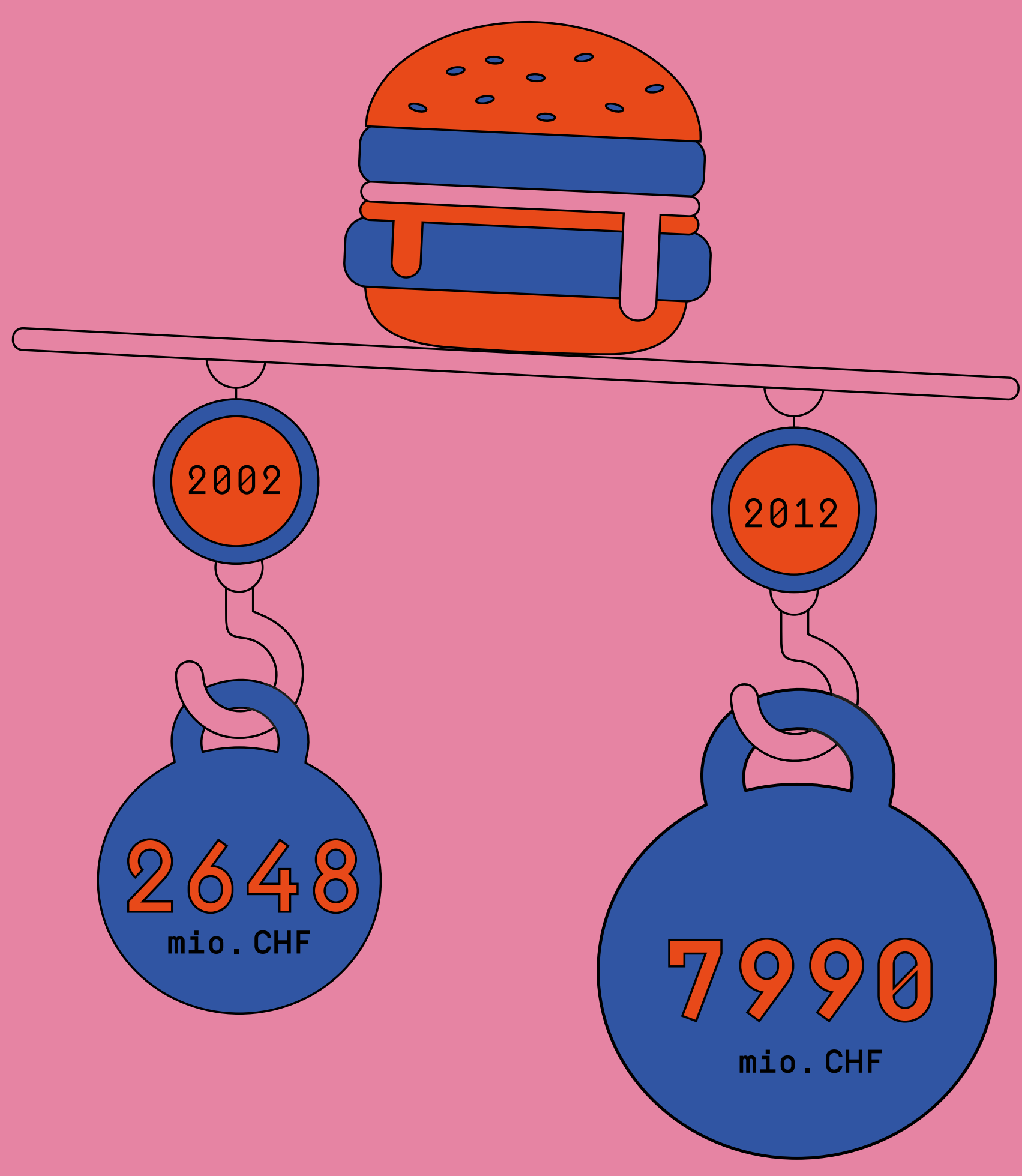

et consommer moins de produits d'origine animale comme la viande rouge et la viande transformée.

Le projet "Inégalité sociale" " a étudié les habitudes alimentaires des personnes vivant en Suisse romande, et a identifie les raisons qui les dissuadent de mange sainement. Moins de $40 \%$ des repondants de l'Enquête suisse sur la santé considerent encore les prix êlevês des denrees alimentaires comme un obstacle à une ali-

Réduire les prix
des aliments sains

c. bid.

Encourager une alimentation saine au travail

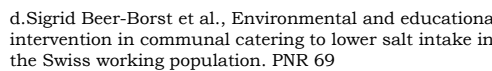

D'autres obstacles à l'alimentation saine ont souvent ete cités, comme le goût pour la bonne chair, le manque de temps, les contraintes du quotidien ou le manque de volonté.

Étant donnée la difficulté de changer les nombreuses raisons personnelles motivant les habitudes alimen taires, les chomenter dour des mesures extensives qui ne se focalisent pas sur certains groupes de population. Ils proposent de réduire le prix des aliments sains, particulièrement des fruits et des légumes, en encouragean par exemple la production locale.

En Suisse, environ un million de personnes actives mangent, au cours de la semaine, dans des restaurant d'un service de restauration ont par conséquent, une influence considérable sur la santé d'une large frange de la population suisse.

Deux projets du PNR 69 ont développé différentes idées sur la maniere dont les entreprises peuvent aider leur personnel à manger plus sainement. Leurs resultats contribuent à l'avancee vers l'objectif d'assurer une alimentation saine sur le lieu de travail, tel qu ill est ennutrition.

Le projet "Consommation de sel " $^{\mathrm{a}}$ a exploré des manières d'encourager la population suisse à s'alimente de manière équilibrée et moins salée. Actuellement, l'apport journalier de sel par personne excède largement les cinq grammes recommandés par l'Organisation mondiale de la santé.

Les chercheuses et chercheurs ont examiné sept organisations dotées de restaurants d'entreprise en Suisse alé mant sensibilisé les employés des entrepris Dune part, ils frant une formation sur la nutrition, suivie de contrôles de santé trimestriels. D'autre part, les chercheurs on assisté les équipes de cuisine dans la planification et la mise en ouvre de mesures pour réduire la teneur en sel des plats habituellement proposés. 
Malgré le fait que les plats du jour contenaient presque autant de sel à la fin de l'année d'intervention qu'au début (teneur médiane en sel de $4,4 \mathrm{~g}$ au lieu de 4,5 cipants est passée de $8,7 \mathrm{~g}$ à $8,1 \mathrm{~g}$ par jour. Alors que la consommation journaliere de sel chez les femmes est restée inchangée à $7 \mathrm{~g}$, une valeur déjà inférieure à l'objectif intermediaire pour la consommation de sel en Suisse celle des hommes est tombée de 10,4 à $9,2 \mathrm{~g}$ par jour mée était plus grande quand les valeurs mesurées au début de l'êtude étaient élevées. Pour les femmes, l'âge et le poids jouent également un rôle dans la réduction des quantités de sel consommées. Le programme de formation a eu un effet positif sur la santé des hommes et des femmes, qui ont développé leur sensibilité concernant la

À la lumière de leurs conclusions qui montrent que dans un environnement alimentaire favorable - des for des changements d'habitudes alimentaires pertinents pour la santé, les chercheurs recommandent d'inclure systématiquement la nutrition dans la promotion de la santé au travail. Ils proposent d'introduire les valeurs de référence pour la teneur en sel comme critères dans les labels de santé existants dans les restaurant d'entreprise.

\section{Activer des motifs de}

\section{environnementaux}

e. Claudde Messner e tal. Environmental cues and their
effect on sustananale food intake. PNR 69 Le projet "Stimuler la santé "e a aussi abordé la question les habitudes alimentaires. A côté des distributeurs automatiques de snacks et de boissons, ils ont placé des par portion), la consommation moyenne de sel des partisanté et l'alimentation au cours de l'année. ont étudié les effets de stimuli environnementaux sur affiches présentant différents sujets, tels que des sculptures d'Alberto Giacometti ou une fete foraine evoquan le plaisir. Ils ont ensuite evalue leffet de l'affiche sur les choix des consommateurs. Les photos de paysages ou d'activités sportives n'ont pas infuencé la quantité des aliments achetes, mais

L'affiche présentant la silhouette maigre d'une sculpture d'Alberto Giacometti a eu pour effet de diminuer l'appétit des consommateurs. Ces derniers ont mange moins que s'ils avaient utilisé un distributeur sans affiche, ou présentant une image de fête foraine. Le chercheurs concluent donc que les stimuli environnementaux peuvent activer des motifs de santé. Ils son ne doit pas se restion de stimuli relatifs à lalentilstation ou aux cantines.

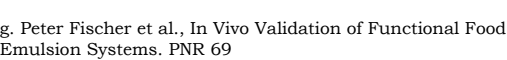

De nouvelles approches carentielles

Deux autres projets du PNR 69 ont donné des résultats susceptibles d'aider les gens à perdre du poids.

Les chercheurs du projet "Prévenir l'obésité "f $^{\mathrm{f}}$ ont développe un instrument utilisant un echantillon d'air expire pour determiner si le corps metabolise les graisse au moment de la mesure. Grâce à la spectroscopie pa laser, lappareil mesure la concentration des molecules d'acetone dans le souffle. Le corps humain produit ce d'énergie qu'il en reçoit.

Les tests indiquent que la concentration d'acétone dan l'air expiré est un biomarqueur fiable pour mesure l'équilibre énergétique dans le corps humain: plus elle est élevée, plus le déficit énergétique est important.

De tels instruments de mesure peuvent donc aider des patients obèses à contrôler leurs efforts pour perdre du poids, et les motiver à continuer. Ceci sinscrit dan cherche à fournir des marqueurs individuels pour un suivi quantitatif d'une exposition au risque ou d'une pathologie donnée.

Un developpement plus approfondi est nécessaire pou réduire la taille de linstrument, et ainsi permettre une application pratique plus simple.

Dans le projet "Functional Food" attaché des gouttelettes de graisse à des émulsions qui ont ensuite examiné dans quelle mesure ces émulsions prolongeaient le sentiment de satiété après avoir mangé. Leurs investigations ont révélé que ces émulsions déclenchent un signal de satiété chez les animaux auss bien que chez les êtres humains. Ces émulsions fonctionnelles peuvent donc permettre de mieux contröler l'apport energetique des personnes en surpoids. Toutefois, les chercheurs soulignent qu'une utilisation géneralisee, par exemple dans des sauces à salade, derielles des émulsions.

Les questions abordees dans le cadre du PNR 69 ne visent pas seulement à diminuer les excès alimentaires. Elles portent aussi sur les manières d'éviter les carences en vitamines et en

Plus de deux milliards de personnes dans le monde, en premier lieu des femmes et des enfants, souffrent de dont la diminution de la performance, l'anémie et une susceptibilité accrue aux maladies. Les compléments alimentaires actuellement sur le marché ne résolven pas le problème, car les composés du fer sont difficiles à digérer ou ont un impact négatif sur le goût, l'odeur ou la couleur des aliments. 
nouvelle approche basée sur la nanotechnologie un permet d'ajouter le fer à l'aliment ${ }^{\mathrm{h}}$. Bien que les nanoparticules de fer aient une bonne biodisponibilité et n'affectent pas le goût, elles s'oxydent fréquemment et forment des agregt
plus les utiliser.

Les chercheurs ont développé un matériel hybride qui stabilise les nanoparticules de fer. Celles-ci adherent constituées d'une protéine comestible du lait, la bề ta-lactoglobuline, un sous-produit de la production de fromage. Lors de tests réalisés sur des rats, le groupe de recherche a établi que les nanoparticules de fer ne se redissolvent pas avant d'entrer dans l'environnement acide de l'estomac, après quoi elles sont rapidement absorbées par le corps.

La nouvelle matière hybride étant neutre au goût, de longue conservation et bon manch a produire, les che ficatif dans la lutte contre la carence en fer notamment dans les pays en développement où l'affection est particulièrement répandue.

Le groupe de recherche du projet "Fibres alimentaires" a analysé les propriétés chimiques du béta-glucane céréalier. Cette fibre alimentaire contribue à réduire les chercheurs ont analysé les effets de la transformation des aliments sur le béta-glucane, ainsi que sur plusieurs interactions moléculaires spécifiques impliquan le béta-glucane.

Le projet permet de mieux comprendre certains effets benefiques du beta-glucane, grace à ses interaction avec les acides biliaires, le fer et la mucine gastrique. Les chercheurs encouragent les décideurs et les praticiens à aider les consommateurs à mieux comprendre industries alimentaires à appliquer les connaissances made des cardiovasculaires, de diabètes et d'obésité.

Le projet "Vitamine $\mathrm{D}$ » a étudié l'apport en vitamine $\mathrm{D}$ chez les femmes enceintes en Suisse, et a révélé par des possèdent trop peu. grossesse est le facteur déterminant le plus important du rachitisme infantile, qui peut également entraîner une mauvaise croissance foetale et néonatale ${ }^{16}$. acquises sur cette fibre alimentaire, afin de produire des La valeur moyenne de vitamine $D$ dans le sang est plus
élevée en été qu'en hiver. Les femmes venant du Tessin, la partie la plus ensoleillee du pays, sont moins exposées au risque de développer une carence en vitamine D que les femmes de Zurich. Les femmes ayant une peau foncée sont particulièrement sujettes à de bas niveaux de vitamine $D$

Le groupe de recherche conclut que les directives suisses actuelles en matière de supplementation en vitaenceintes d'une carence en vitamine $D$, soit parce que les doses recommandées sont trop basses, soit, plus probablement, parce que les femmes ne prennent pas les compléments régulièrement. Les médecins praticiens doivent être plus attentifs à la supplémentation en vitamine D durant la grossesse.

\section{Les bases d' une}

et durable

k. Matthias Stolze et al, Sustainable and healthy diets:
Trade-offs and synergies. PNR 69

\section{Augmenter 1 'apport}

la grossesse

j. Sabine Rohrmann et all, Evaluation of Vitamin D Status
and Its Determinants in Switzerland. PNR 69
Les habitudes alimentaires de la population suisse ont d'importantes conséquences. La manière dont les aliments sont produits, transformés et consommés n'influence pas seulement la santé de la population, mais aussi l'environnement, l'économie et la société dans son . rable $n^{\mathrm{k}}$ ont développé plusieurs scénarios d'avenir, afin d'évaluer ces impacts avec une plus grande précision. saine et a un systeme de production alimentation plus durable d'un point de vue environnemental et social.

Le premier scénario présume qu'en 2050, la population suisse suivra les recommandations de la pyramide alimentaire suisse. Le deuxième scénario, "FeedNoFood" envisage des habitudes alimentaires principalement mosuppose qu'en 2050, en Suisse, le fourrage du bétall sera entièrement composé dherbe et de sous-produits tuelle dans laquelle la production de l'alimentation du bétail et de celle des êtres humains sont en concurrence, aura cessé d'exister. Le scénario pyramidal et le scénario "FeedNoFood" partent tous deux de l'hypothèse que la population suisse consommera moins de viande et plus de légumineuses d'ici 2050. Le troisième scénario ne prevoit aucun changement dans les habitudes alimentaires du pays.

L'analyse a montré que les deux scénarios alternatif des alient des ajustements similaires dans les habitude viande est considérablement réduite et compensée par des légumineuses. Ce changement induit des synergies positives entre la durabilité et la santé publique: une alimentation moins riche en viande est plus saine, et améliore en mème temps la durabilité écologique et sociale de la production alimentaire. Les modèles montrent que réduire la consommation de tivees par la conscience environnementale. Ce scenario 


\section{La pyramide}

En outre, l'analyse montre que l'autosuffisance nette du secteur alimentaire suisse pourrait augmenter grâce à la baisse des importations de fourrage pour la production mateurs diminueraient à mesure que leurs dépense alimentaires en produits animaux coûteux baisseraient. Sur le plan macroeconomique, un tel changement se traduirait cependant par une baisse de la valeur ajouté pour le secteur alimentaire suisse.

Toutefois, l'analyse des scénarios montre également que les changements d'habitudes alimentaires peuvent entraîner certaines tensions. Il y a d'importantes contradictions dans les recommandations alimentaires actuelles en matière de santé et les modèles d'impact sur la santê. Par exemple, la viande devrait être consommée comm source de mineraux, de proteines et de vitamines. Or, des etudes epidemiologiques montrent que de légères augmentations des isques de plusieurs types de cancers peuvent être associes à une consommation eleveé de diction concerne les substituts à la viande: s'il faut importer des produits d'origine végétale comme les légumneuses, l'impact social dans les pays exportateurs doit être pris en compte. Ces problèmes doivent être résolus afin de réduire la confusion chez les consommateurs.

L'étude a identifié un autre conflit dans l'expansion de la production biologique. Une proportion plus élevée d'aliments issus de lagriculture biologique pourrait contriToutefoid en raison des rendements plus faibles il résulterait davantage d'importations si les habitudes alimentaires restaient inchangées, ce qui augmenterait l'impact environnemental à l'étranger.

Bien que les fruits et les légumes soient considérés comme sains, lis sont rapidement perissables et contrbuent à augmenter les quantités de dechets alimentaires a tous les niveaux de la chaine d'approvisionnement the logistique plus efficace et une meilleure conservation l'environnement, à l'avenir.

Ces exemples montrent comment les modèles contribuent, substantiellement, à comprendre les divergences entre une vision strictement axée sur la production agricole, et une vision globale du système alimentaire.

Le projet a également montré qu'une alimentation saine et une production alimentaire durable ne peuvent rêsulter dactions isolees au sein du systeme alimentaire. de l'alimentation et de l'agriculture, qui à l'heure actuelle constituent trois domaines indépendants les uns des autres, devraient être coordonnés dans un cadre systémique, visant un système alimentaire sain et durable au bénéfice de la population.

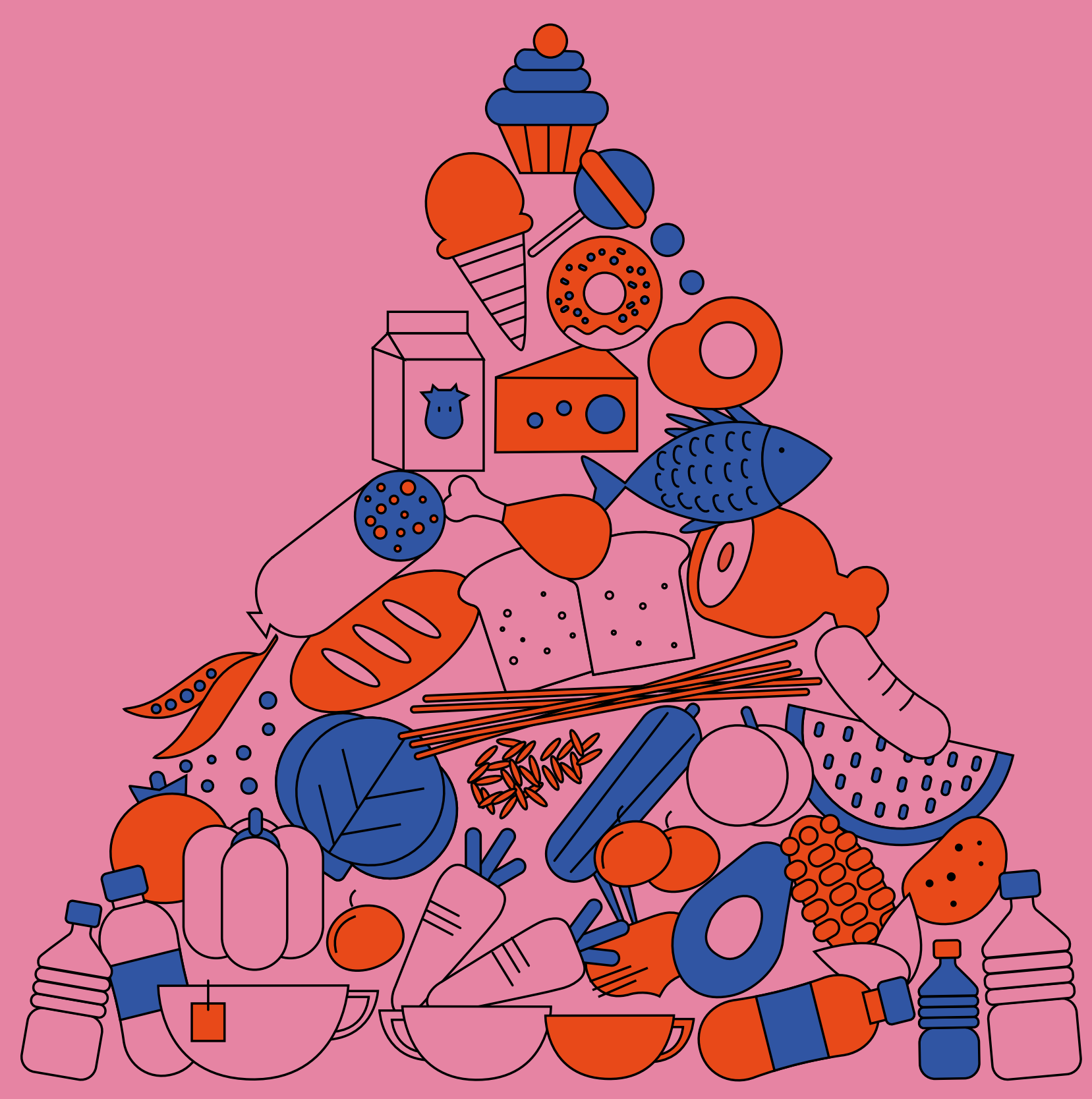




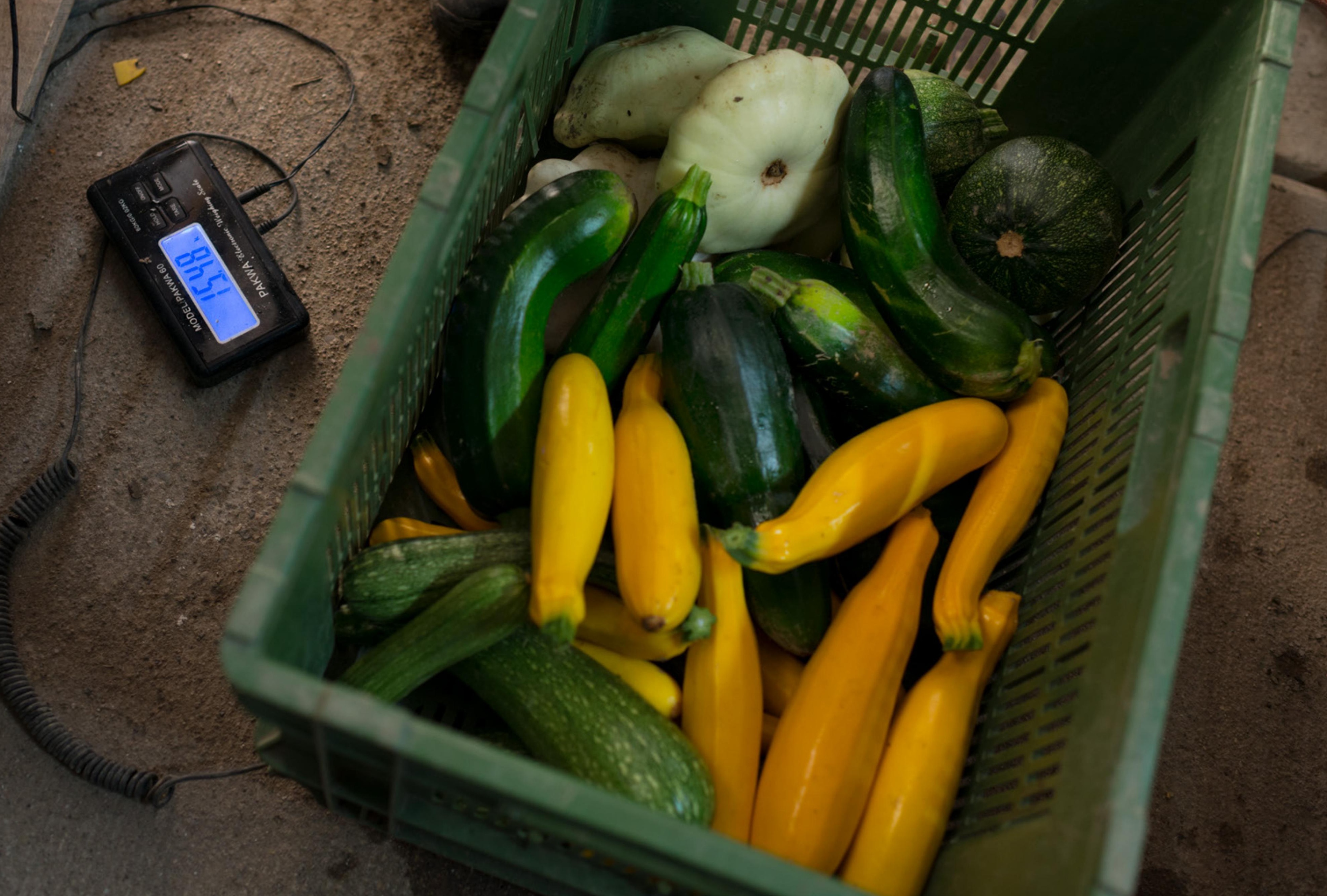


Les scientifiques travaillant dans le cadre du PNR 69 ont développé diverses propositions pour produire de la viande, du lait et des légumes d'une manière plus respectueuse de avoir des effets positifs directs sur la santé humaine.

\section{Un système alimentaire suisse plus durable}

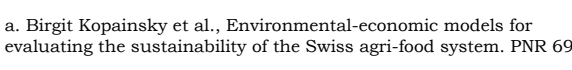

Performance environnementale des exploitations laitièr des régions
suisses

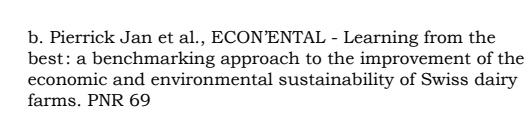

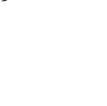

émission réduire

les émissions issue

des stabulations
de vaches laitiêres Le projet "Système agro-alimentaire durable $»^{\mathrm{a}}$ a établi
que le système agro-alimentaire était responsable de près d'un tiers de tous les impacts environnementaux en Suisse. Etant donné que ce secteur ne compte que pour $7 \%$ de la valeur ajoutée brute nationale, cela signifie qu'll contribue de façon disproportionnee à la charge environnementale. Une coordination entre la production agricole, lindustrie de transformation, le commerce de gros, le commerce de détail et la consommation alimen teigne une meilleure durabilité.

Dans ce chapitre, le terme "durabilité" se réfère principalement à l'impact environnemental du système alimentaire, mais aussi à ses aspects sociaux et économiques.

Dans le cadre du projet "Production laitière durable "b des chercheuses et chercheurs ont évalué la perfordans les régions de montagne suisses. Sur la base de leurs travaux ils recommandent que dans le cadre des évaluations de la performance environnementale, une distinction soit faite entre la performance environnementale locale et globale, les deux devant toujours être prises en considération.

Le groupe de recherche a identifié des facteurs qui ont le potentiel d'améliorer simultanément la performance performance économique des exploitations laitières des régions de montagne. Ces facteurs sont l'agriculture biologique, des chefs d'exploitation ayant un niveau de formation élevé et, dans une moindre mesure, un faible recours aux concentrés pour l'alimentation du bétail des exploitations plus grandes et une activité agricole à temps plein.

L'élevage laitier est responsable d'une part importante des émissions de gaz à effet de serre et d'ammoniac liées à l'agriculture. L'ammoniac non seulement nuit aux éco-
systèmes sensibles, mais il peut également contribuer à systemes sensibles, mais il peut egalement contribuer à
la formation de particules fines pouvant nuire à la santé humaine ${ }^{18}$. 
Pour ces raisons, l'un des Objectifs environnementaux pour l'agriculture $e^{18}$ est une réduction de $40 \%$ des émissions d'ammoniac en Suisse par rapport à 2005. Dans fiques ont examiné l'efficacité de différentes mesures de réduction des emissions d'ammoniac. Ils ont découver que des mesures architecturales visant les sols souilles, la principale source d'ammoniac, sont prometteuses.

La première mesure architecturale testée était la

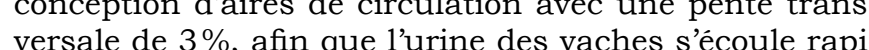
dement vers une rigole de collecte centrale. Un racloir à fumier automatique circulait 12 fois par jour pour permettre un drainage régulier. Les premiers résultats du système doté d'une pente ont montré une réduction de $20 \%$ des êmissions d'ammoniac par rapport au système de référence sans pente.

La seconde mesure de construction, qui a résulté en une diminution significative des emissions d'ammoniac, naient sur une aire d'affouragement surélevée avec séparations. Comme très peu d'excréments et d'urine sont déposés sur cette plateforme, les aires de circulation fortement souillées étaient réduites. De plus, le racloir a fumier automatique pouvait nettoyer frequemment l'allee de circulation derriere les stalles d'alimentation, sans déranger les vaches en train de manger.

En plus de réduire les émissions d'ammoniac, les bots, ainsi que l'hygiène de l'étable.

Les deux mesures ont été intégrées dans la nouvelle "Ordonnance sur les ameliorations structurelles dans l'agriculture "1. L'ordonnance prevoit une aide financière aux agricultrices et agriculteurs qui mettent en seuve ces mesures dans le cadre de
velles constructions d'écuries.

Tout comme l'élevage laitier, la production de viande crée un impact sur l'environnement. Durant les trente dernières années, la consommation moyenne de viande en Suisse a chuté de 60 à 50 kilogrammes par année ${ }^{20}$. Le porc reste la viande de predilection dans le pays, comme en atteste la part de $22 \mathrm{~kg}$ pour lannee 2017. Les chercheuses et chercheurs du projet "Porcs en

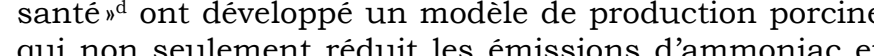
de gaz à effet de serre, mais qui améliore aussi simultanément la santé de l'animal et son bien-être. Pour réduire les émissions de gaz à effet de serre et d'am-
moniac, le groupe de recherche a exploré l'efficacité protéique des porcs boliser les protéines efficacement, moins le volume des dejections protéiques qui se trouvent dans le purin, et qui sont une source de nitrogène et d'ammoniac, est grand.

Les chercheuses et chercheurs ont aussi mené une étude auprès de 112 élevages de porcs pour savoir où et sation d'antibiotiques devait être augmentée en réponse.

Selon les chercheurs, les facteurs suivants sont essentiels pour un élevage porcin utilisant peu d'antibiotiques: une bonne hygiène dans les auges, des quantités appropriées de nutriments spéciaux pour les jeunes animaux, et le fait d'eviter que des animaux à differents stades de maturité ne se retrouvent dans la mème porcherie. Reduire lutilsation d'antibiotiques dans lélevage porcísistances aux antibiotiques chez les bactériestion dent pathogènes pour les êtres humains et les animaux.

\section{Limiter la pollution}

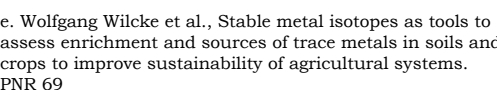

Deux projets du PNR 69 étaient dédiés à l'impact en vironnemental des cultures. Le projet charge en métaux" " a evalue les niveaux de cadmium, de cuivre, d'uranium et de zi rages suisses.

Les résultats indiquent que les pratiques agricoles des cinquante dernières années ont causé une accumulation de ces métaux dans les sols. Ce constat est préoccupant pour deux raisons. D'une part, des concentrations élevées de métaux peuvent altérer la fertilité des sols. D'autre part, les métaux sont absorbés par les plantes, et ils sintroduisent ainsi dans la chaine ali-

Sur une période d'une année, le groupe de recherche a prélevé plusieurs échantillons de sols, issus de troi de trois pâturages où du fumier est épandu. Ce procédé lui a permis de mesurer les flux de métaux entrants et sortants.

Les scientifiques ont établi que les quatre métaux s'etaient accumules dans les couches superieures du sol, dans tous les champs étudiês. Les engrais mineraux phosphorés sont la principale source de cadmium et duranium. Pour lisiter la pollution des sols en metaux duire une nouvelle valeur indicative pour l'uranium dans les engrais minéraux et de vérifier soigneusement cette valeur, de même que celle pour le cadmium. 

De plus, l'accumulation des deux métaux pourrait être
évitée en augmentant l'utilisation d'engrais recyclés composés de cendres de boues d'épuration, à conditio qu'ils soient issus de processus qui appauvrissent la teneur en métaux lourds.

Le fumier est la source première de zinc et de cuivre dans les sols. Les deux métaux sont utilisés comme additifs fourragers, puis excr
se retrouver dans le purin.

Pour réduire l'afflux de cuivre et de zinc à l'avenir, les scientifiques recommandent que les lignes directrices relatives à l'ajout de cuivre et de zinc dans les aliments
pour animaux soient strictement appliquées et que la distribution de fumier liquide soit optimisée dan les zones agricoles. En outre, ladoption de variétés de portent efficacement le zinc devrait être encouragée.

\section{Changer la rotation}

les infections fongiques

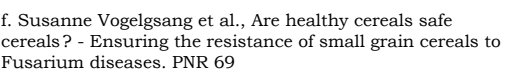

\section{Deux tiers de 1 'empreinte} ecologique sulsse se

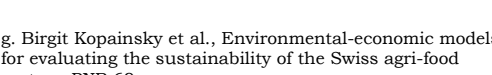
Le projet "Céréales sûres ${ }^{\mathrm{f}}$ a comparé la résistance de
differentes variétés de grains aux attaques du Fusarium. ment réduire les infections par Fusarium dans les céréales. Ces champignons representent un risque pou la sante silis contaminent des céreales, car ils liberent des toxines dangereuses connues sous le nom de mycotoxines.

Lors des essais en chambre climatique et sur le terrain l'orge s'est montrée plus sensible au Fusarium lorsdes conditions plus fraîches $\left(10^{\circ} \mathrm{C}\right)$ ou plus chaudes $\left(20^{\circ} \mathrm{C}\right)$. Par comparaison avec le blé, l'orge s'est montrée généralement plus vulnérable, à toutes

Les résultats confirment en outre qu'une modification de la rotation des cultures est la manière la plus efficace de prevenir une contamination par les mycotoxines. L'orge précédente était du maïs. L'avoine devrait quant à elle être semée après des cultures de céréales à gros grains.

Dans le cadre du PNR 69, le projet "Système agro-alimentaire durable "ह a simulé les possibles developpements du système alimentaire suisse. Les chercheuses et chercheurs ont applique deux modèles environnele systèm et econoniques. Lun dine des émissions de gaz à effet de serre du pays. La question principale du projet était de savoir com-
La plupart des gaz à effet de serre peuvent être attribués à la production de viande et de lait. En outre, l'agriculture a un impact environnemental par son usage
considérable de surfaces et d'eau. À contrario, l'impact environnemental de l'industrie de transformation alimentaire, du commerce et de la distribution est relativement bas, alors que ces secteurs génèrent le plus de valeur ajoutée.

Les chercheurs du projet ont aussi montré que près de deux tiers de l'empreinte écologique de la consommation alimentaire suisse surviennent à l'étranger tion humaine, de fourrage et de matières premières. Le constat que la majorité des impacts environnementaux a lieu à l'etranger se réfère aux impacts environnementaux agrégés selon la methode de la saturation écologique, aux émissions de gaz à effet de serre

\section{Renforcer les partenariats} entre producteurs et

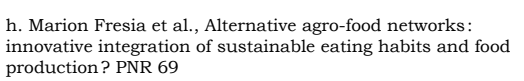

Les chercheurs du projet "Panier bio " ${ }^{\text {h }}$ soutiennent que les efforts pour rendre l'approvisionnement alimenstratégies intégrées qui visent les producteurs et les consommateurs.

Le projet indique qu'encourager la population à manger des produits locaux et saisonniers soutient non seule ment les producteurs locaux, mais aide aussi à promoudernières années, l'intérêt pour les réseaux alimentaires régionaux a augmenté en Suisse. Ces réseaux proposent un abonnement à un lot de produits régionaux et créent un partenariat direct entre les agriculteurs et les consommateurs, leur permettant de partager les risques si, par exemple, les recoltes sont faibles en raison d'une mauvaise météo.

Le groupe de recherche travaillant sur le projet "Panie a découvert que l'agricultures en Suisse romande. mité (ACP) évolue d'un phénomène de niche à des systèmes plus rigoureusement structurés. Mais ces systemes semblent avoir de la peine à obtenir lacceptation de larges segments du public. $80 \%$ des membres de ces réseaux alimentaires ont une education de niveau superieur et appartiennent à la classe moyenne ou superieure.

Dans les trois études de cas, le système d'abonnemen de plus dautonomie aux producteurs, car les paniers sûre. De plus, plusieurs agricultrices et agriculteurs estiment que leur travail est mieux reconnu grâce à leu partenariat avec les consommatrices et consommateurs. Simultanément, l'agriculture contractuelle de proximite encourage des habitudes alimentaires saines et durables. 


\section{Les impacts de la consommation alimentaire suisse}
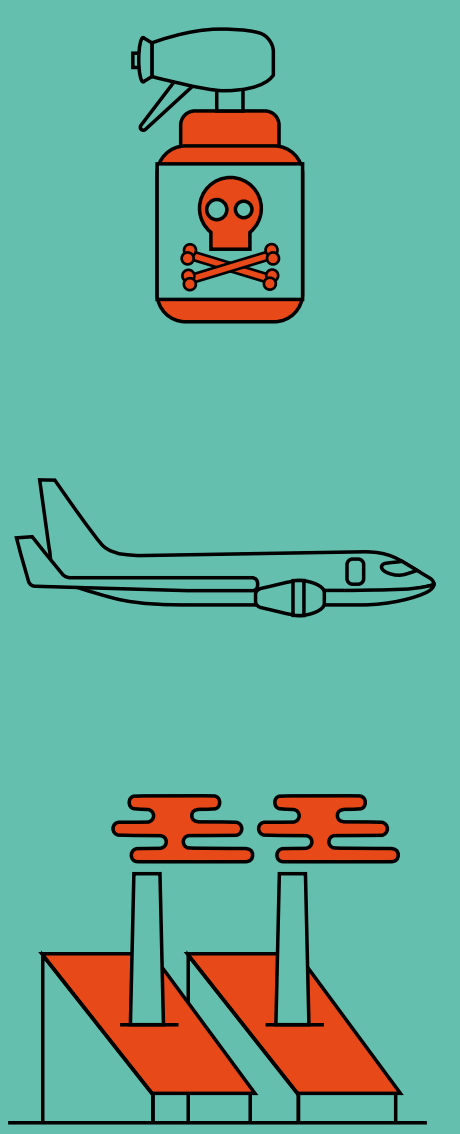
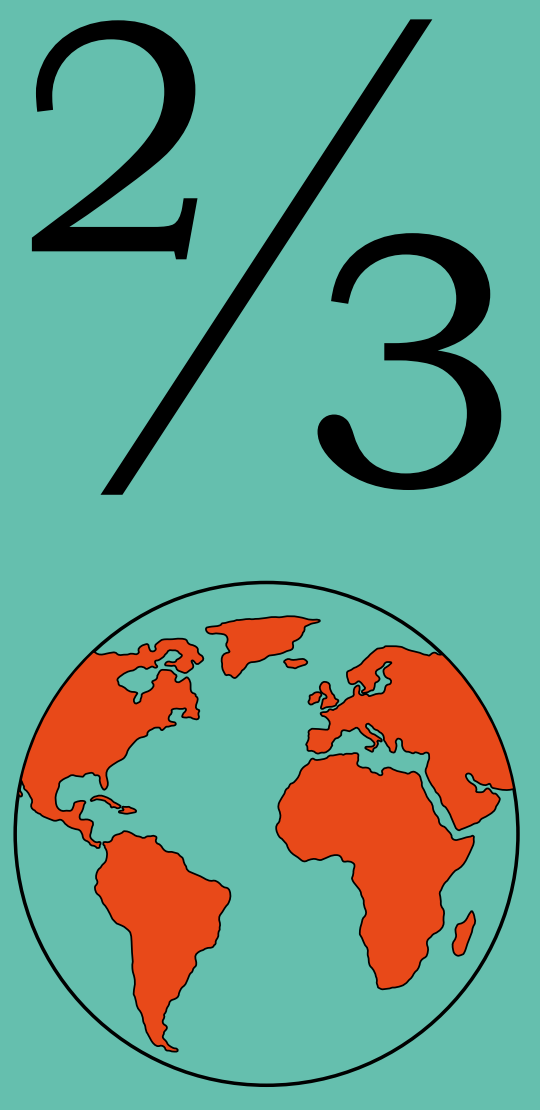

de l'empreinte écologique de la consommation alimentaire suisse surviennent à l'étranger via limportation d'aliments humaine, de fourrage
hume et de matières premières.
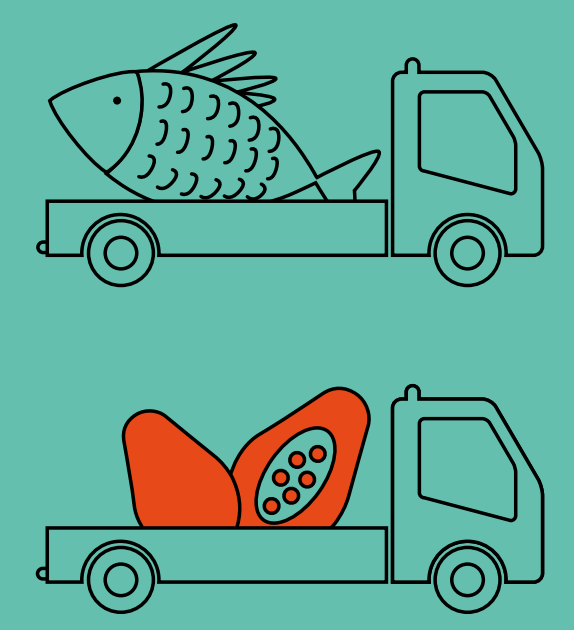

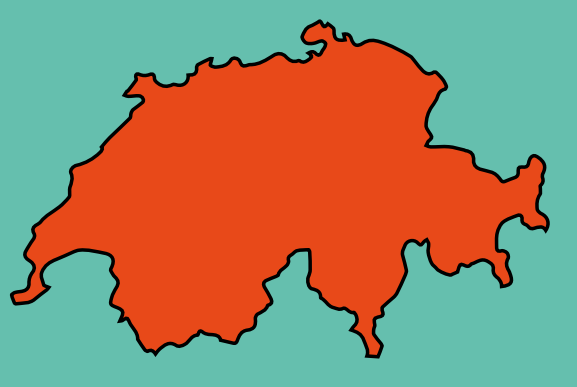
Les chercheurs recommandent par conséquent de pro-
mouvoir des projets d'agriculture contractuelle de proximité, par exemple en augmentant le nombre de partepubliques et semi-étatiques, comme les crèches, les écoles, les homes et les maisons de retraite. nariats entre les producteurs locaux et les institutions

Réduire les pertes et le gaspillage alimentaires: un levier pour rendre le système alimentaire plus efficient et durable

Dans le monde, près d'un tiers de l'alimentation humaine produite finit non-consommée10. La statistique pour la Suisse est similaire, selon l'Office fédéral de l'environnement $(\mathrm{OFEV})^{11}$ : cela représente 2,6 millions de tonnes gaspillées par année, dont les deux tiers sont considérés comme évitables. En moyenne annuelle, chaque habitant gaspille $190 \mathrm{~kg}$ d'aliments encore consommables.

On estime que $37 \%$ des pertes alimentaires se produisent dans l'industrie; le secteur de la restauration compte pour $11 \%$ et le commerce de détail pour $4 \%$ des pers. $9 \%$ des pertes se produs grande dans les ménages des consommatri

Selon l'Organisation des Nations Unies pour l'alimentation et l'agriculture ${ }^{10}$ le gaspillage alimentaire se refere au fait de jeter de la nourriture ou d'utiliser d'une autre manière les aliments destines a priori à l'alimentation humaine (usage non-alimentaire). Toujours selon la même source, les pertes alimentaires peuvent être définies comme "la diminution de nourriture, en quantité ou en qualité. Ce sont des produits agricoles ou piscicoles destinés à la consommade qualité percue dans leur valeur nutritionnelle, économique ou en baisse de sécurité sanitaire". Elles se produisent tout au long de la chaîne d’approvisionnement alimentaire. Sachant que deux tiers de l'empreinte écologique de la consommation alimentaire suisse se produisent à l'étrangeri, l'impact de la

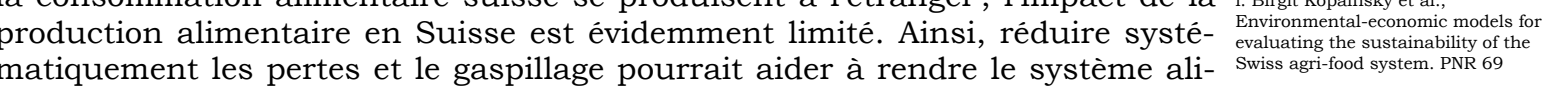
plus durable dans un laps de temps relativement court. Le gouvernement s'appuie pour linstant sur des mesures volontaires et emplo une variété d'activités de communication pour sensibiliser le public ${ }^{1}$

Cependant, le gouvernement suisse a ratifié les Objectifs de développement dua diviser par deux le gaspillage des aliégalement de réduire les pertes alimentaires au niveau de la production a cole, du commerce et de l'industrie de transformation d'ici 2030. Pour cela, l'Office fédéral de l'environnement (OFEV) développe actuellement une stratégie de veille et de réduction du gaspillage alimentaire ${ }^{1}$

Dans le cadre de cette stratégie, l'OFEV a publié un rapport résumant l'ampleur du gaspillage alimentaire et des impacts environnementaux en Suisse, en collaboration avec lETH Zurich'. L'objectif de ce rapport est didentifier les point sensibles touchant à linvironnement, den deduire des mesures efficaces pour campagne de sensibilisation sur le thème des pertes alimentaires, et d'identifier les lacunes majeures dans la recherche.

Un des problèmes inhérents à ce type d'analyse est de savoir comment mesurer les pertes et le gaspillage. Au niveau de l'Union européenne, en mai 2019 , la Commission européenne a décide dintroduire une methodologie commun pour la mesure des pertes et du gaspillage alimentaires dans $1^{\prime} \mathrm{UE}^{22}$ 
Les pertes et gaspillage

\section{alimentaires}

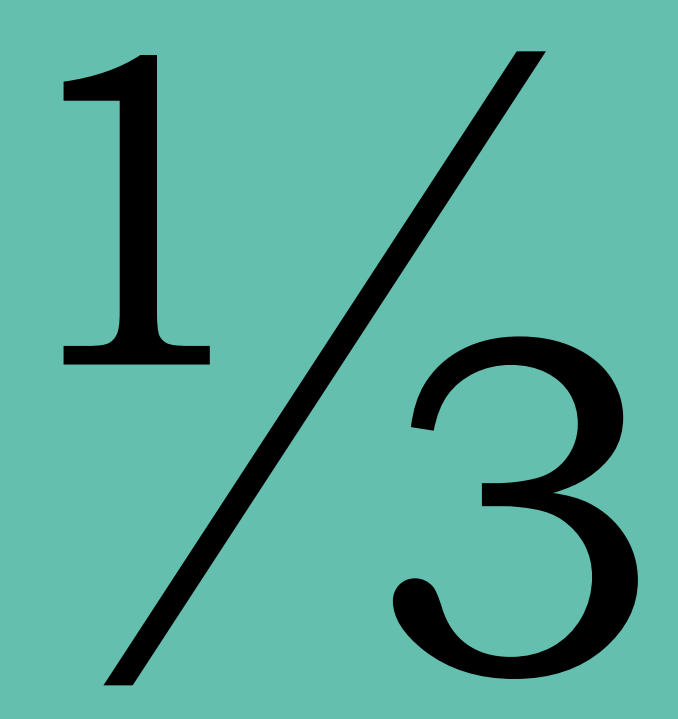

de l'alimentation humaine produite dans le monde finit
non-consommée.

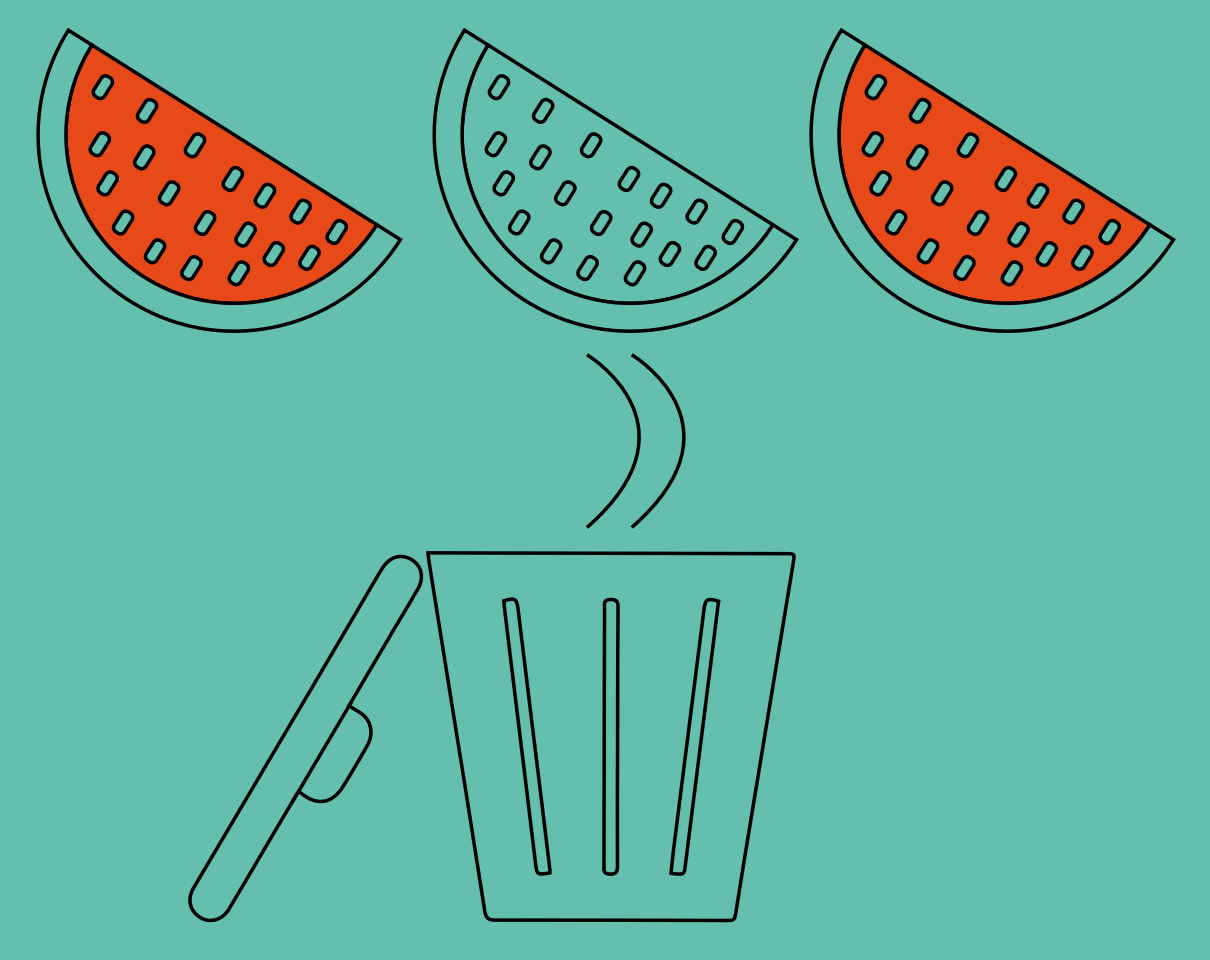

En Suisse, cela représente
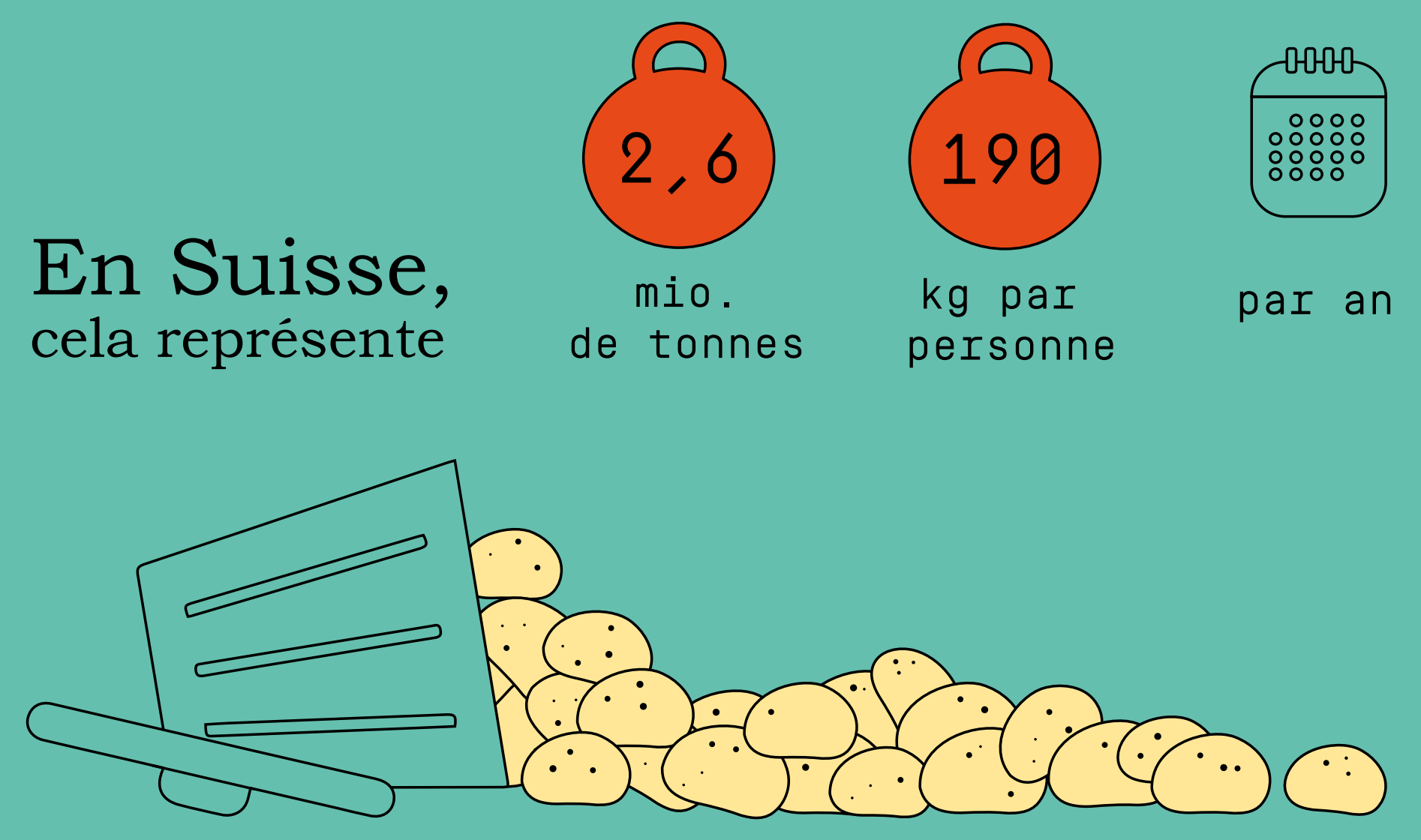
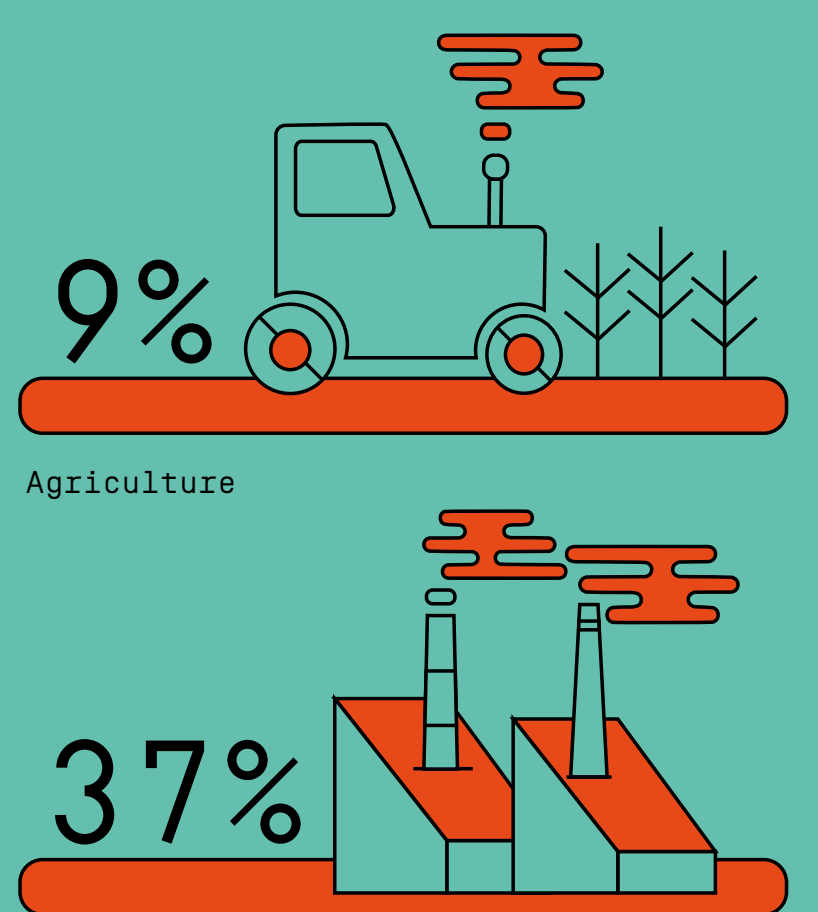

Industrie

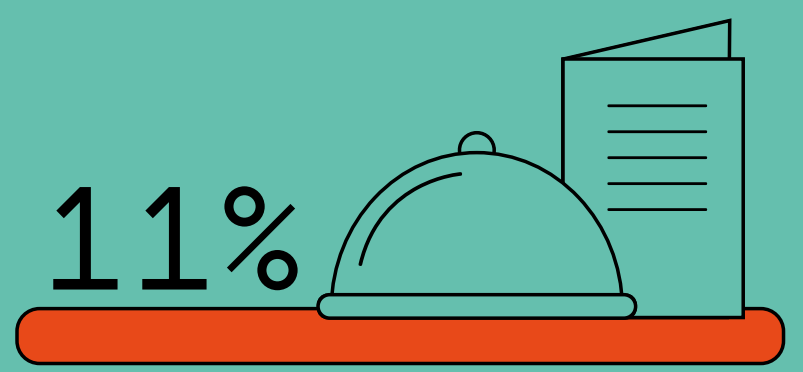

Gastronomie

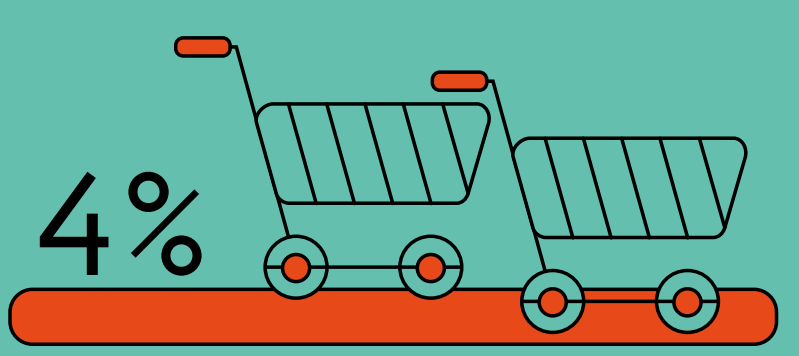

Commerce de détail

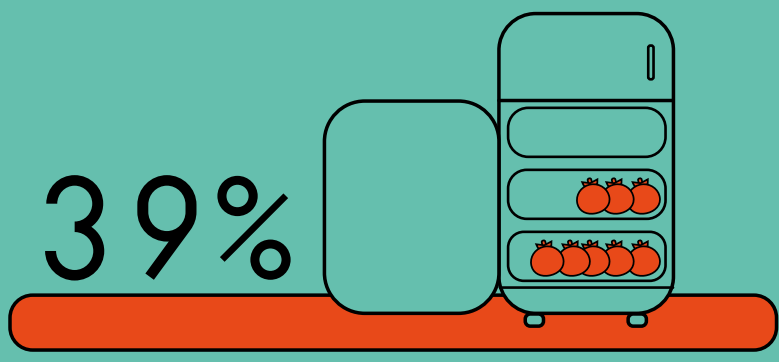

Consommateur 
Une étude sur les pertes

de pommes de terre

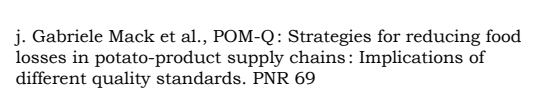

$0000 \bigcirc \bigcirc \bigcirc \bigcirc$ 000000000 0000000000 0000000000 00000000 0000000000

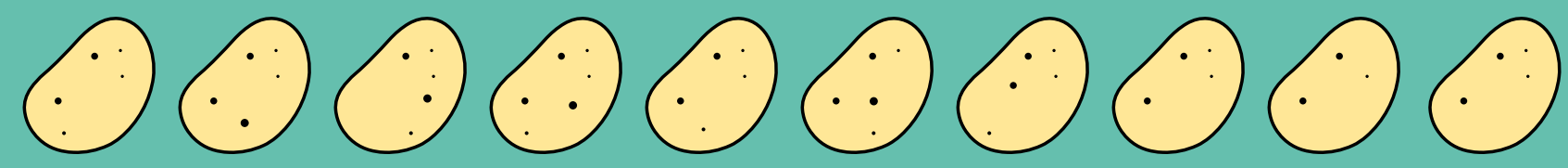

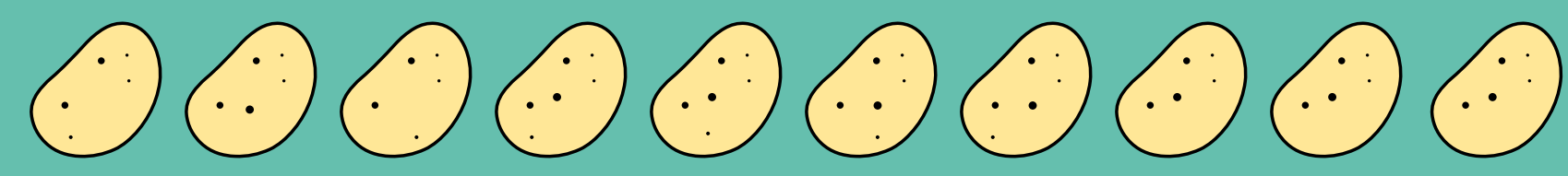
$\because \because \because \because \because \cdots)$ 0000000000
Innover dans les dates conservation alimentaire

k. Cornelia Palivan et al, Protet
preserve food quality. PNR 69

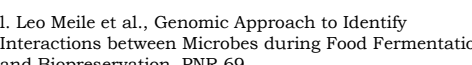

Le problème général des pertes et du gaspillage alimenpon ampleur sont connus (voir le contexte en page 43). Cependant, il ne sera possible de réduire les te gaspillage alimentaires efficacement que Te dispose dinformations detaillees sur chaque etape de la chaine de valeur agro-alimentaire. A ce jour, il
n'existe que peu d'études exhaustives sur les différentes denrées alimentaires.

Dans le cadre du PNR 69, une telle étude a été menée tout au long de la chaine de valeur de la pomme de terre moins de $53 \%$ de la récolte de pommes de terre n'est pas consommée par les êtres humains. Près de la moitié des pertes se produisent au stade de la ferme. Cette vision détaillée de la chaîne de valeur de la pomme de terre permet aux scientifiques de proposer des mesures pour diminuer les pertes et le gaspillage alimentaires.

Le projet suggère que les standards esthétiques de la pomme de terre soient assouplis et que les pommes de terre qui ne remplissent pas les critères pour la trans-
formation soient utilisées comme fourrage. En outre, les chercheuses et chercheurs notent que des emballages plus petits et résistants à la lumière pourraient aider les consommatrices et consommateurs à acheter des quantités adaptées à leurs besoins.

Ces propositions sont spécifiquement adaptées à la chaine de valeur de la pomme de terre et ne peuven pas ercheurs recommandent d'analyser de la même manière les chaînes de valeur agro-alimentaires d'autres produits, comme différents types de légumes. Cela permettra d'identifier l'ampleur et les causes du gaspillage à chaque étape de la chaîne de valeur agro-alimentaire, et d'offrir une base pour développer des mesures effcaces pour la réduction des pertes et du gaspillage.

Le projet "Nano conservation " $^{\mathrm{k}}$ offre une alternative aux ro pé des labels intelligents pour les emballages, qui réagissent par exemple aux changements de $\mathrm{pH}$ dans les aliments. Ainsi, quand les aliments deviennent acides en se périmant, leur déterioration est indiquee par un changement de couleur ou de fluorescence des labels. Cette technologie n'est pas encore prête pour le marché; des recherches supplementaires sont nécessaires sur d'autres systemes dindicateurs, sur l'acceptation des production d'emballages de ce type.

Un autre projet nommé "Bactéries conservantes" " a étudié la possibilité d'utiliser des bactéries lactiques pour conserver les aliments plus longtemps. Les chercheuses et chercheurs ont développé un processus permettan de sélectionner les cultures bactériennes possédant les meilleures qualités de conservation. 

L'utilisation de telles cultures dans les processus de
production pourrait augmenter la durée de conservation des aliments et améliorer la sécurité alimentaire en réduisant les contaminations. Cela pourrait être le cas pour les contaminations par staphylocoques. Cette bactérie libère dans les produits alimentaires des substances toxiques pour les êtres humains. D'autres exemples de contamination bacterienne incluent la listéria et la salmonelle, deux bacilles pathogènes répandus. de souches de bactéries lactiques qui ont des propriétés très diverses et qui peuvent être utilisées à de nombreuses fins.

Cependant, il n'existe pas de gestion coordonnée des donnees sur les souches bacteriennes qui ont ete etuutiles. Le groupe de recherche recommande de mieux exploiter le potentiel de conservation alimentaire des bactéries. Ceci inclut le partage des informations concernant plateforme centrale pour des partenaires publics et privés, et accessibles librement et directement.

Dans le cadre du projet "Staphylocoques" " , les chercheuses et chercheurs ont analysé les facteurs de risque d'intoxication alimentaire au staphylocoque. Ils on étudié limpact de quatre facteurs sur la formation des toxines du staphylocoque: des niveaux elevés de sel, de sucre, de saumure et dacide lactique ( $\mathrm{pH}$ faible), ces et le stockage des aliments.

Il en ressort que la bactérie libère moins de toxines dangereuses, appelees enterotoxines, dans un environnement qui contient des niveaux élevés de sel ou de sucre. Mais les chercheurs ont aussi relevé que chaque souch bactérienne réagissait différemment aux facteurs testés.

Pour mieux faire face au risque sanitaire que représente le staphylocoque, les chercheuses et chercheurs recommandent de developper de nouvelles stratégies de détecque sur le nombre de bactéries. Le développement de
tels systèmes de détection pourrait augmenter la sécuduire les pertes alimentaires.

Deux groupes de recherche participant à l'initiative européenne Joint Programming Initiative "A Healthy Die for a Healthy Lifen (JTH

Il est indéniable que l'alimentation influence la santé. Ce processus varie toutefois d'une personne à l'autre: la disposition génétique, le métabolisme et les facteurs environnementaux jouent un rôle. Il manque aujourd hui des méthodes précises pour mesurer les efrets de lalimentation sur la santé. Grâce à de nouveaux biomarqueurs, diées scientifiquement et classees comme potentiellemen que sur le nombre de bactéries. Le développement de rité alimentaire pour les consommateurs et aider à ré- il est possible de mieux observer les conséquences de l'alimentation sur la santé et de les prédire pour certain groupes de la population. Le but du projet "Mirdiet" marqueurs genetiques fournissant des indications sur les effets de la nutrition sur la sante. Laccent a ete mis sur certaines molecules d'ARN appelees microRNA. Ces acides ribonucléiques non codants circulent dans le sang et contribuent à la régulation gênique. L'etude a analys sur différents microRNA. De manière générale, les résuttats ont été limités par les difficultés techniques posées par la mesure des microRNA circulant dans le sang. Les scientifiques recommandent de continuer à chercher des biomarqueurs de la prise alimentaire, malgré la complexité des méthodes visant à quantifier les molécules. Des avancees sur le plan technique pourraient permettre de surmonter ces obstacles et de mesurer plus aisement les microRNA circulants, qui restent prometteurs pour la

Aujourd'hui, les recherches nutritionnelles sur la consommation d'aliments reposent surtout sur des questionnaires. Une nouvelle méthode promet des rèsultats plus précis: la science pourrait analyser plus humaine les effets des denrees alimentaires sur la sante à-dire la somme des substances présentes dans le sang et l'urine suite à la consommation de ces denrées. De tels biomarqueurs ne sont aujourd'hui validés que recherche "FOODBALL" 'o'est proposé de (i) mettre en place les outils technologiques nécessaires à la caractérisation de ces biomarqueurs, en particulier la métabolomique nutritionnelle et les banques de données permettant de quantifier et d'identifier ces biomarqueurs, ainsi que de (ii) conduire des études nutritionnelles humaines afin dildentifier des biomarqueurs spécifiques a groupes alimentaires.

Ainsi, les chercheurs d'Agroscope et de l'Université de Lausanne qui ont participé au projet FOODBALL ont pu iner des biomarqueurs du métabolisme humain qui corroborent la consommation de lait, de fromage et de l'ingestion des produits laitiers, on trouve des molècules derivees du lactose dont l'apparence dans le sang et lurine des participants est indicatrice de leur capacité à digérer le lactose. Ces résultats mettent en avan le potentiel de la recherche conduite par le consortium personnalisée. De plus, les chercheurs suisses ont identifié des métabolites dérivés des acides aminés tryptophane et phénylalanine comme marqueurs de l'ingestion d'aliments fermentés. Ces résultats ont ouvert la voie, au travers d'une étude humaine observationnelle, donc conduite en conditions réelles, à de nouveaux travaux dont le but est de caracteriser limpact des aliments fermentés sur la sante. 


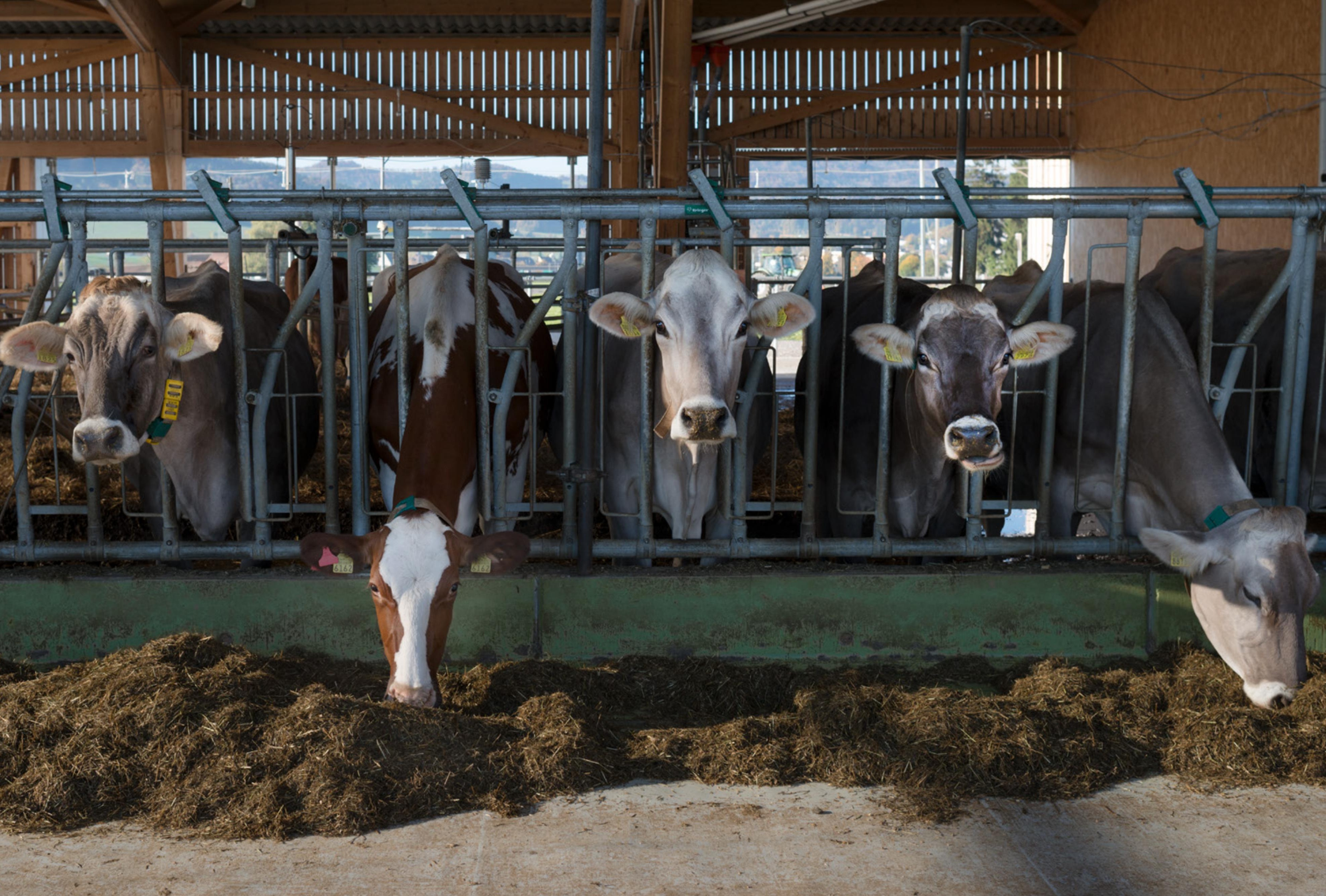




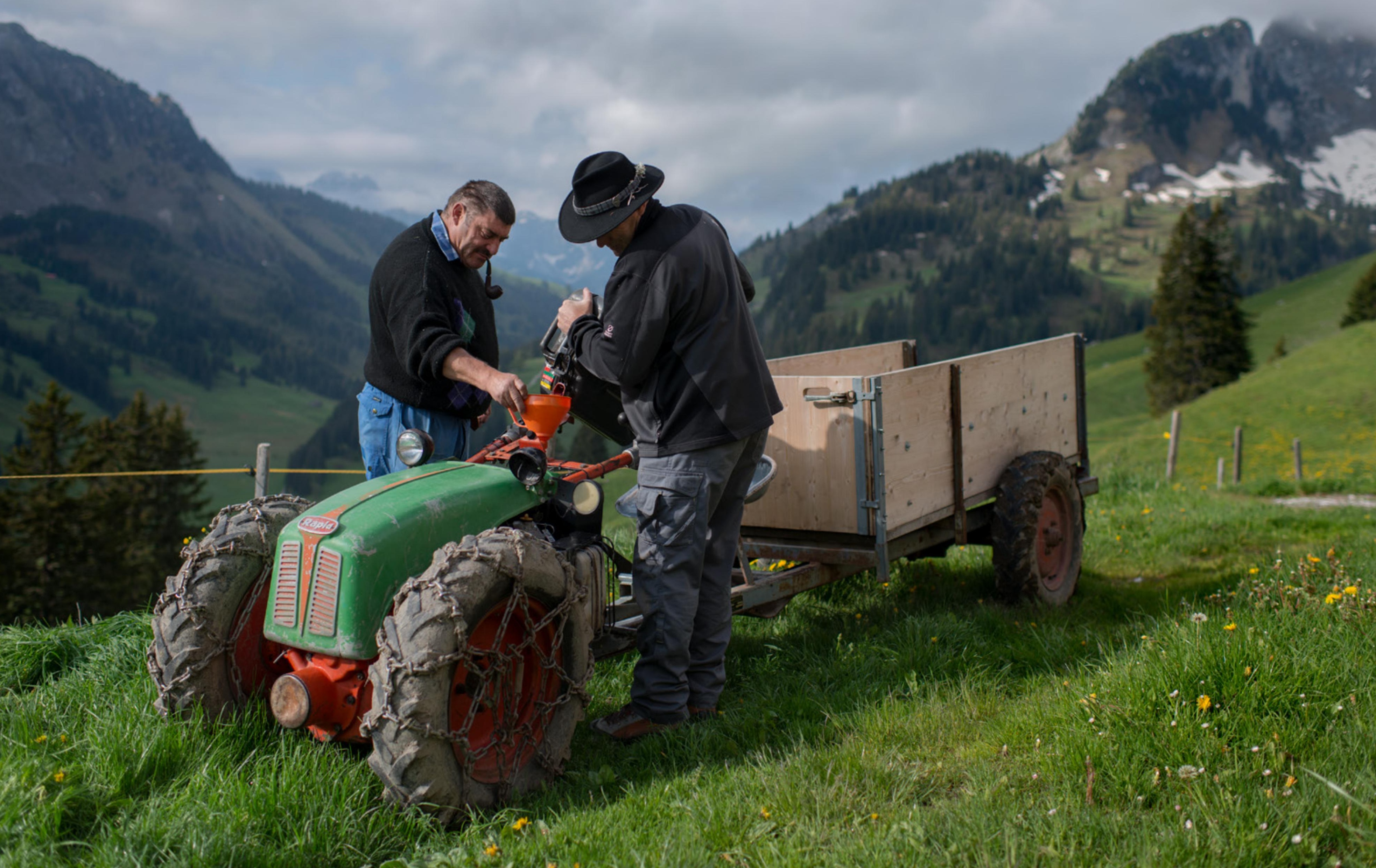




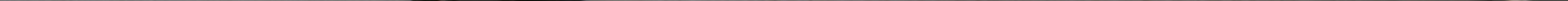




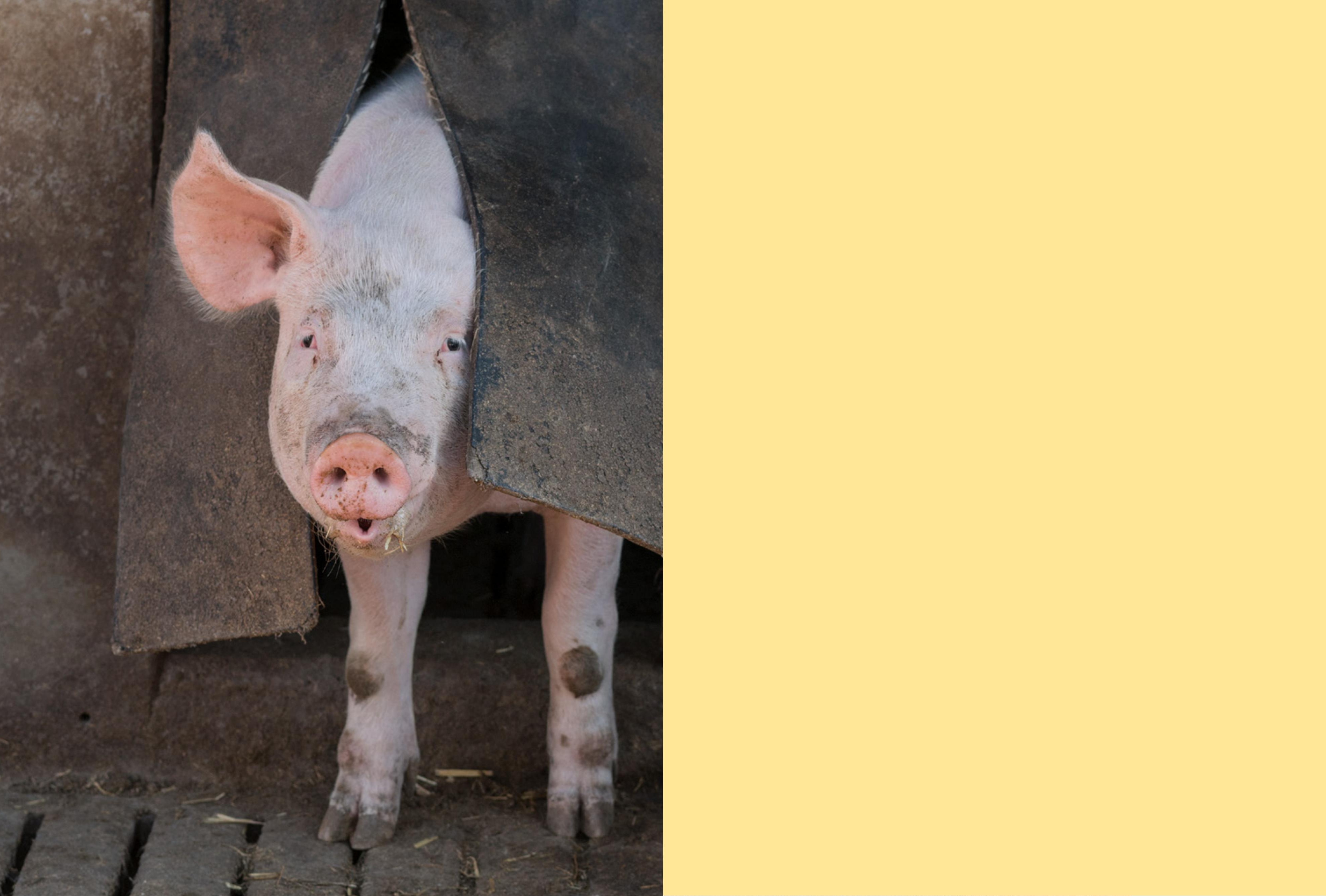




\section{Analyse des politiques}

\section{suisses ayant}

une incidence sur

le système alimentaire

Un groupe de recherche du PNR 69 a analysé les domaines politiques qui influencent la manière dont le système alimentaire est régi en Suisse - les politiques agricoles, de sécurité Suisse, les politiques de sécuritén anaire et de santé publique suivent des objectifs fondamentalement coherents. Dans le domaine des politiques agricoles, qui est établi depuis plus
longtemps, on observe plusieurs intêrêts contradictoires.

Des politiques agricoles avec des objectif Le système alimentaire suisse est largement façonné par
trois domaines politiques: les politiques agricoles, les exigences en matière de sécurité alimentaire et les politiques de santé publique. Une analyse des politiques a été menée dans le cadre du PNR 69 pour examiner ces trois domaines. L'équipe de recherche s'est intéressée aux problemes cibles par ces politiques, ainsi qu'aux mesures concrètes mises en cuvre pour les résoudre. Elle distingue trois types de mesures: les réglementations qui entrainent des sanctions negatives en cas d'information. Ce chapitre résume les résultats de son analyse.

Les politiques agricoles interviennent au début de la chaine de création de valeur du système alimentaire. En Suisse, ces politiques reglementent la production alimentaire de differentes façons. Les deux mesures prinet les réglementations. Les mesures informelles, telles que les campagnes d'information, sont rares.

De nombreuses mesures de politique agricole poursuivent plusieurs objectifs en même temps. La production alimentaire est par exemple soutenue par le biais de subventions. D'autres subventions servent à encourager la préservation des ressources naturelles et le bien-être

Le recours important aux subventions et aux réglementations, ainsi que la multitude d'objectifs qu'elles pour-
suivent, découlent de la longue histoire des politiques agricoles suisses et du grand rôle joué par le gouvernement fédéral.

Certains instruments des politiques agricoles visent à limiter limpact environnen poitiques agrico production agricole. Les instruments sont employés a cette fin depuis

Le domaine politique de la sécurité alimentaire englobe toutes les mesures destinées à garantir que les aliments puissent être consommés en toute sécurité. Ces mesures couvrent toute la chaine de valeur agro-alimentaire, de la production alimentaire à la consommation, 


\section{Le système alimentaire suisse}

Le système alimentaire suisse est largement façonné par trois domaines politiques. Les politiques agricoles, de santé
publique et de sécurité alimentaire utilisent des mesures différentes pour résoudre les problèmes dans ces domaines.

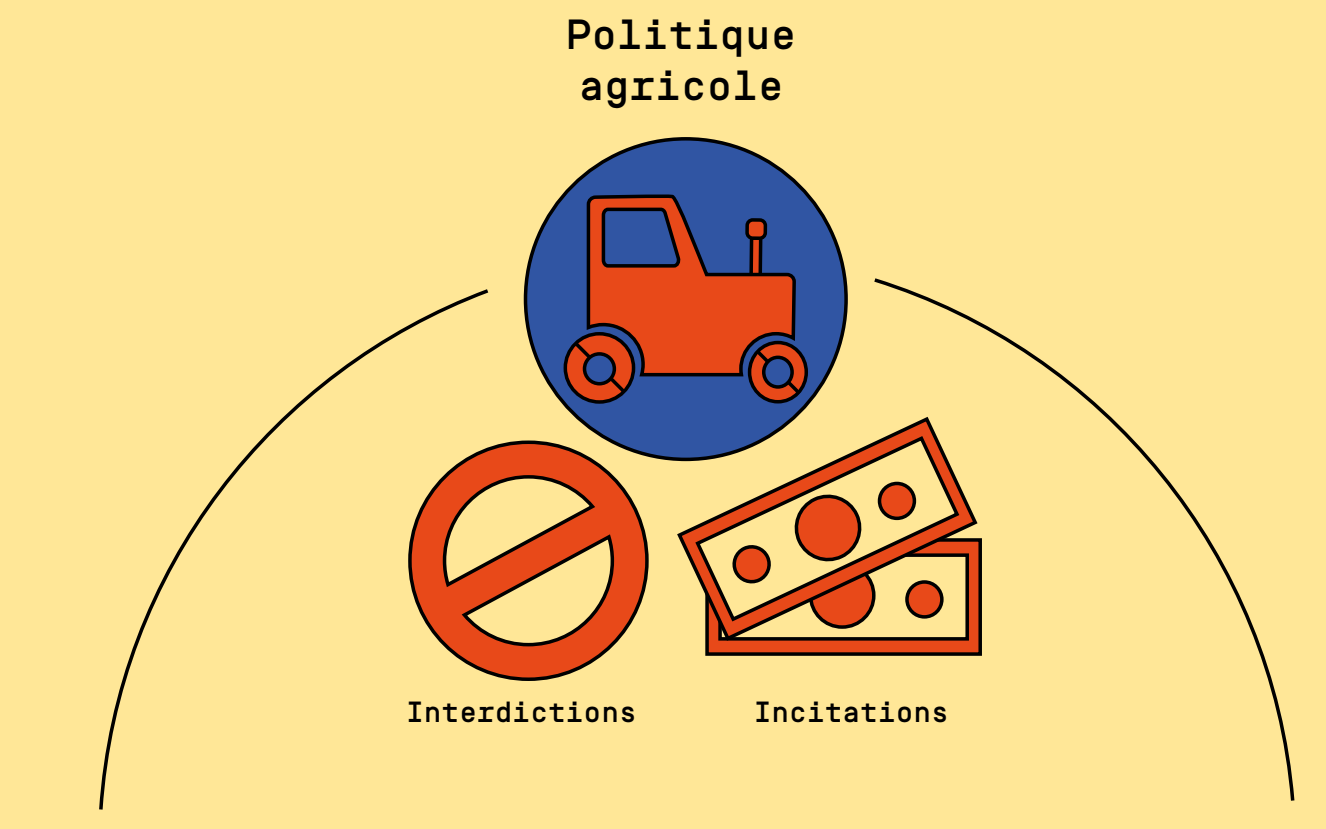

Sécurité

alimentaire
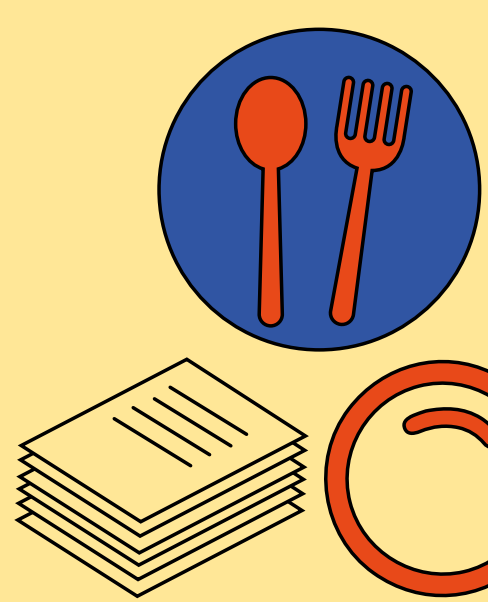

Réglementations

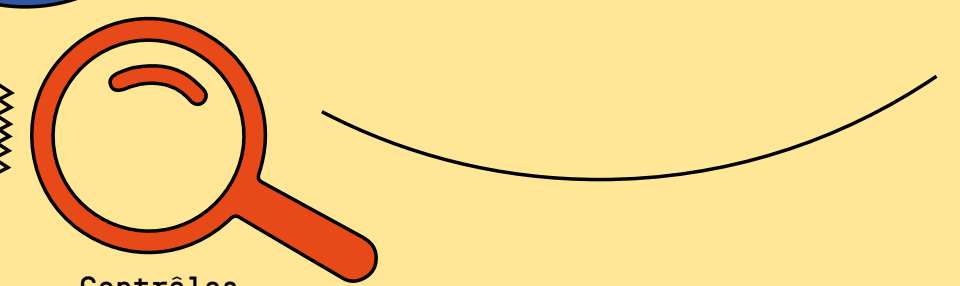

contrôles
Politique de santé publique

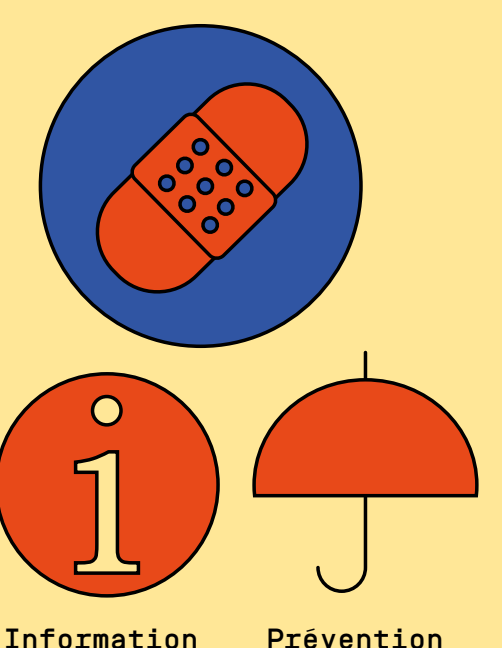

Mesures pour promouvoir l'alimentation saine

Intérêts contradictoire dans les politiques du système alimentaire suisse en passant par la distribution. La sécurité alimentaire
est avant tout garantie par une législation stricte et des systèmes de contrôle. Les politiques suisses de sécurite alimentaire sont relativement cohérentes et la réglementation suisse est totalement harmonisée avec celle de l'Union européenne.

Comme de nombreux aspects de la santé publique sont régis par de nouveaux domaines politiques, qui sont en sont en place dans ce domaine. Ce phénomène explique peut-être pourquoi la plupart des efforts visant à promouvoir une alimentation saine reposent sur l'information $^{23}$. L'objectif des campagnes d'information est de sensibiliser les consommatrices et consommateurs à la nécessite de manger sainement et de leur transmettre Dans le système fédéraliste suisse, la promotion de la sante relève en grande partie de la compétence des can-
tons. La Stratégie suisse de nutrition 2017-2024 contient pas de réglementations ni d'incitations destinées à créer des conditions cadres qui favorisent l'alimentation saine. De ce fait, les mesures politiques de sante publique actuelles sont par essence moins contraignantes que les mesures mises en œuvre dans le cadre des politiques agricoles ou de sécurité alimentaire.

De manière générale, la Suisse met en œuvre peu de réglementations et dincitations qui visent directement limitée empêche le gouvernement fédéral de jouer un rôle plus actif dans la santé publique. Les services de la Confédération doivent donc compter sur la collaboration volontaire de l'industrie et des cantons dans leurs efforts pour promouvoir les décisions alimentaires saines.

Pour ces raisons, les politiques de santé publique qui encouragent activement l'alimentation saine sont relativement peu développées en Suisse.

Depuis 2007, l'Union européenne dispose d'une stratégie globale et non-obligatoire pour les problèmes de santé liés à la nutrition, à la surcharge ponderale et à l'obésité. Une initiative européenne, notamment validée par la Suisse, a aussi ete lancee recemment pour reduire la quantité de sucre dans les aliments transformés ${ }^{25}$.

L'analyse des politiques menée par les chercheuses et chercheurs montre que les politiques suisses de sécurite tifs fondamentalement cohérents. Aucun conflit majeur n'a été identifié, tant dans les différents domaines politiques que dans leurs interactions avec d'autres secteurs. En outre, le groupe de recherche n'a pas observe de conflit au niveau des obligations internationales de la è l'égard de l'Union européenne. 
Points de tension

Les politiques agricoles suisses sont moins cohérentes Dans ce domaine, l'analyse des politiques a mis en lumière plusieurs zones de conflits potentielles. Pa exemple, les politiques agricoles ont deux objectifs bien différents. Le premier consiste à accroître l'accès aux marchés étrangers. Pour avancer vers cet objectif, des accords ont éte negocies avec l'Union europeenne pou eliminer partiellement ou reduire les tarifs douaniers, par exemple. La Suisse a également

Dans le même temps, le gouvernement fédéral impose un cadre réglementaire strict à l'agriculture suisse procedde à des interventions correctives sur le marché. Celles-ci interviennent, par exemple, quand les agricultrices et agriculteurs doivent se conformer à certaines normes environnementales. Compte tenu des objectifs de politique agricole parfois incoherents, les différentes mesures doivent

D'une part, le gouvernement veut que l'agriculture suisse puisse être compétitive sur le marché unique européen d'autre part, il utilise des réglementations relativemen contraignantes pour protéger les producteurs locaux et constamment adaptés pour gérer ces incohérences.

Il existe donc un conflit entre le commerce extérieur et le marché indigène. De tels conflits surviennent par exemple quand les poltiques agricoles visent à garantir lapprovisionnement en produits agricoles tout en - avec dans les deux cas, les conditions préalables du marché libre. Ces tensions dans les politiques agricoles doivent être soigneusement équilibrées.

L'équipe de recherche considère les nombreuses coopérations entre les acteurs étatiques et prives comme une source de tensions politiques supplementaires, dan les trois domaines politiques - l'agriculture, la securite alimentaire et la sante publique. Les parties prenantes paux détaillants ou les geupes de pression - les orgnisations environnementales, associations agricoles ou organisations de la santé, par exemple - jouent un rôle majeur dans le développement et la mise en œuvre des mesures politiques. Des tensions peuvent survenir dans le cadre des collaborations; un effort de coordination par l'Etat est donc nécessaire.

\section{entre les politiques agricoles}

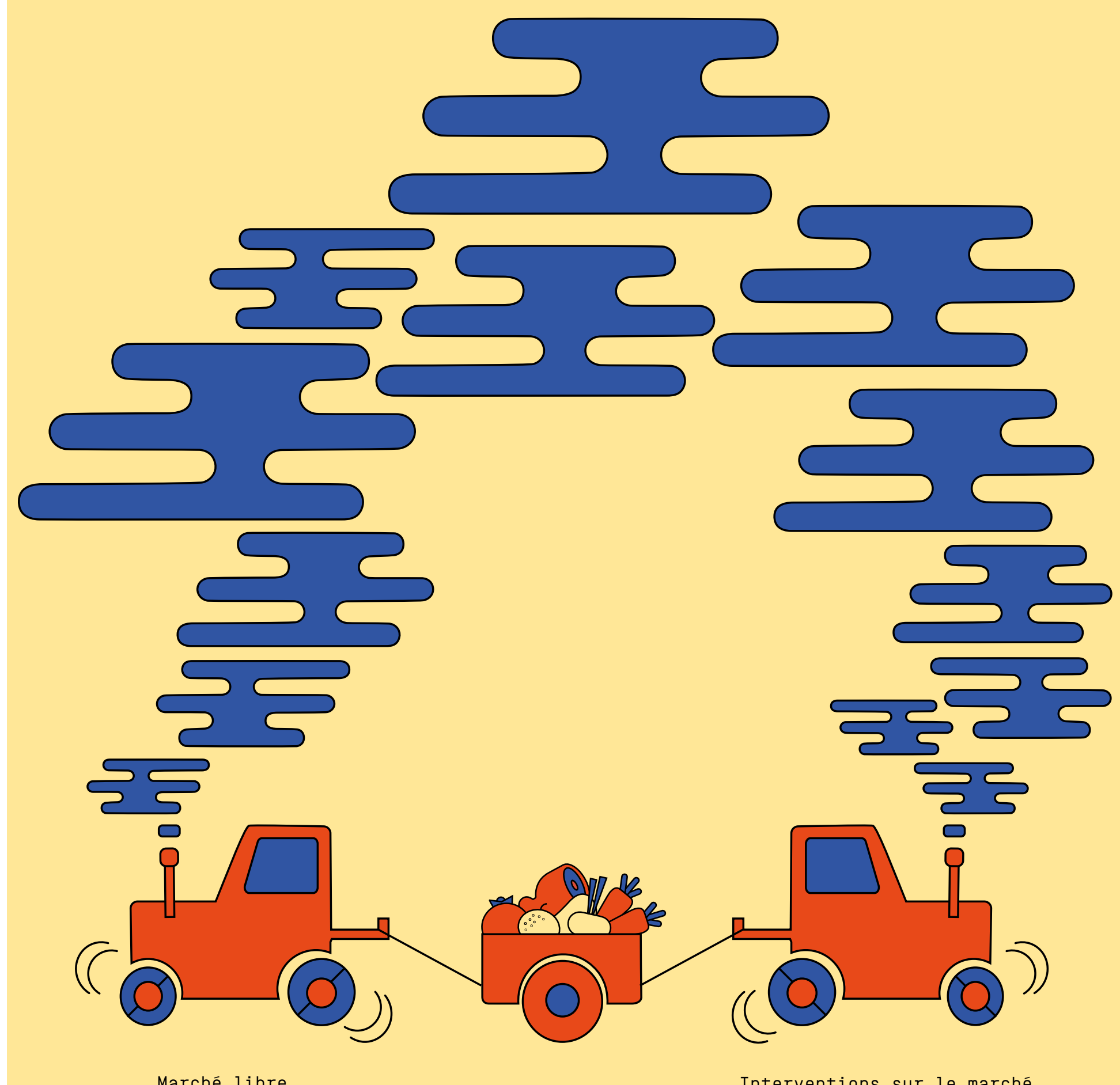

Marché libre

Interventions sur le marché

Il existe plusieurs zones de tension potentielles dans le domaine des politiques agricoles suisses. D'une part, le gouvernement veut que lagriculture suisse puisse être

D'autre part, il utilise des réglementations relativemen contraignantes pour protéger les producteurs locaux et l'environnement. Les objectifs politiques doivent êtr compétitive sur le marché unique européen. 


\section{Impliquer les consommateurs.trices}

L'influence des consommateurs sur les décisions politiques affectant le système alimentaire reste limitée. Afin d'impliquer toutes les parties concernées, l'administration publique et les instances politiques devraient associer les representants des consommatrices et des consommateurs aux decisions politiques, au même titre qu'elles impliquent les producteurs et les industries alimentaires dans l'élaboration du système alimentaire suisse.

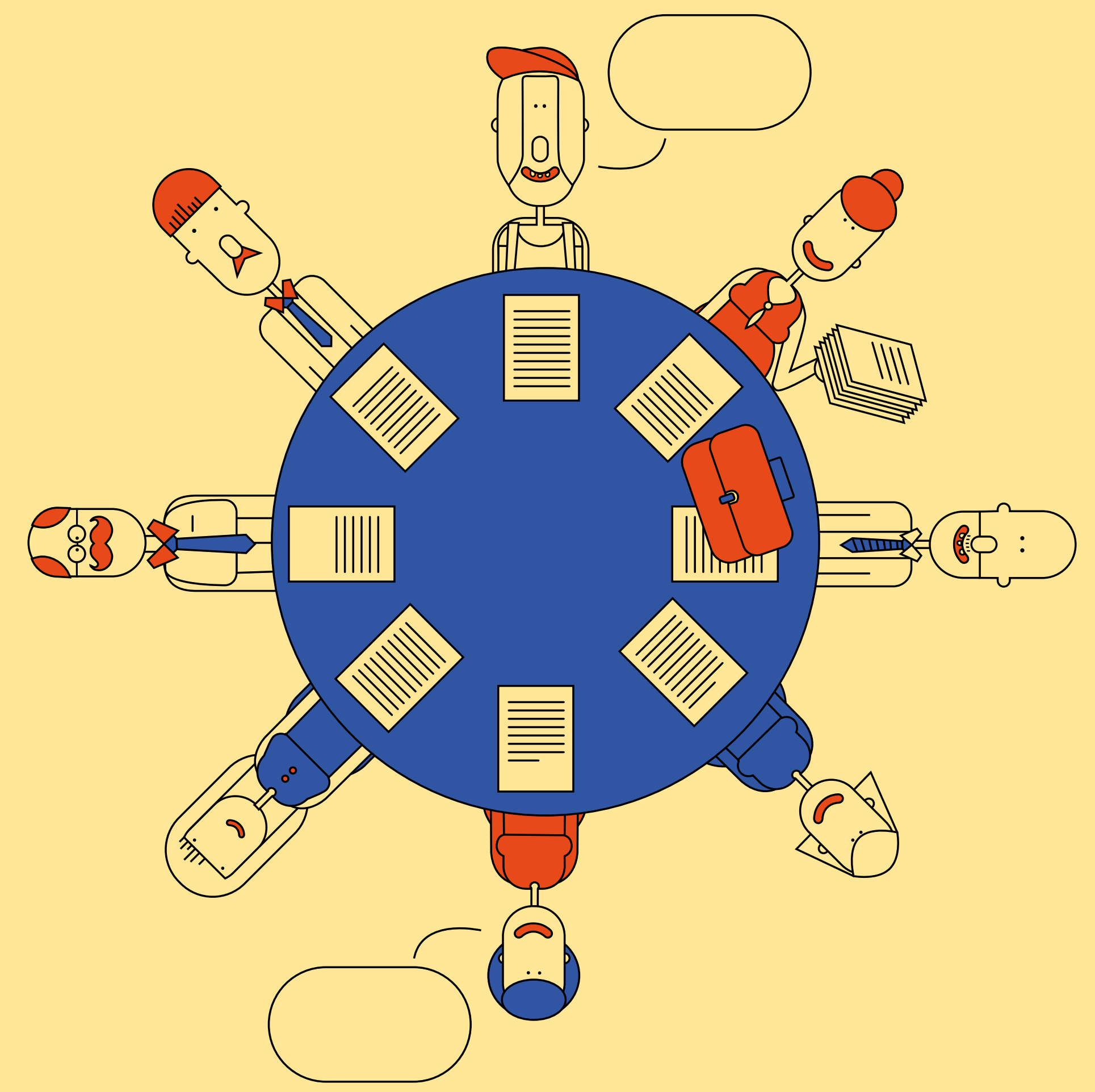

Le projet "Citoyens-consommateurs " du PNR 69 révèle que même si les préférences alimentaires et les comportements de consommation prennent une place toujours plus importante, l'influence des consommatrices et des consommateurs sur les décisions politiques concernan le système alimentaire reste limitée.

Le groupe de recherche recommande diverses mesures pour renforcer l'influence des consommatrices et consomIl s'agit notamment d'étendre le droit de recours des organisations de protection des consommateurs et de confére aux consommateurs le droit de s'associer à des plaintes collectives. Les chercheuses et chercheurs suggèrent aussi à l'Etat d'accorder un plus grand rôle aux consommateurs dans l'exécution de tâches publiques - par exemple, contribuer a la surveillance des denrees alimentaires, comme cest le cas au niveau communal. Le gouveur unt pourrait aussi creer de nouvelles plateformes teurs et les politiques. 


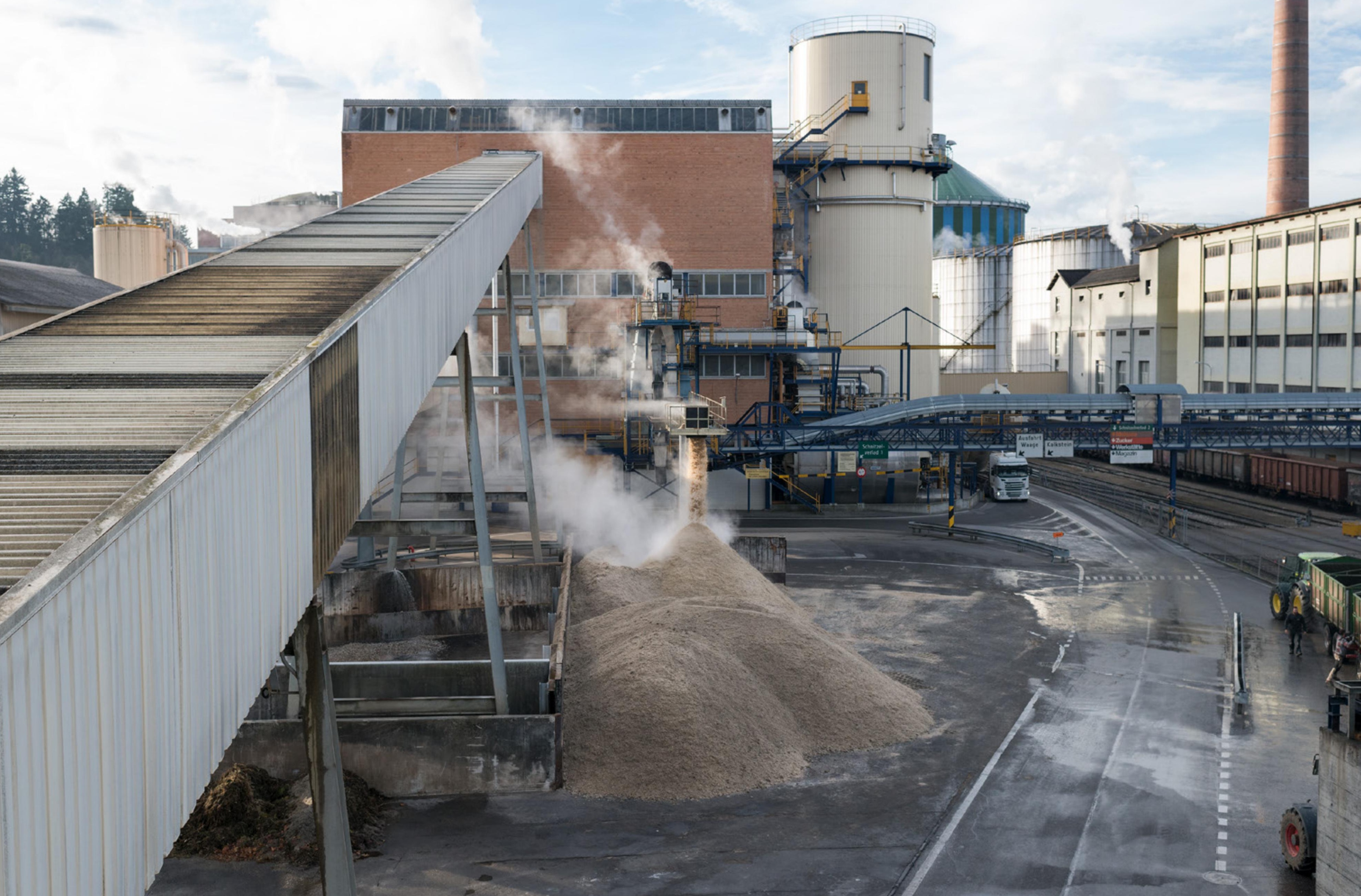




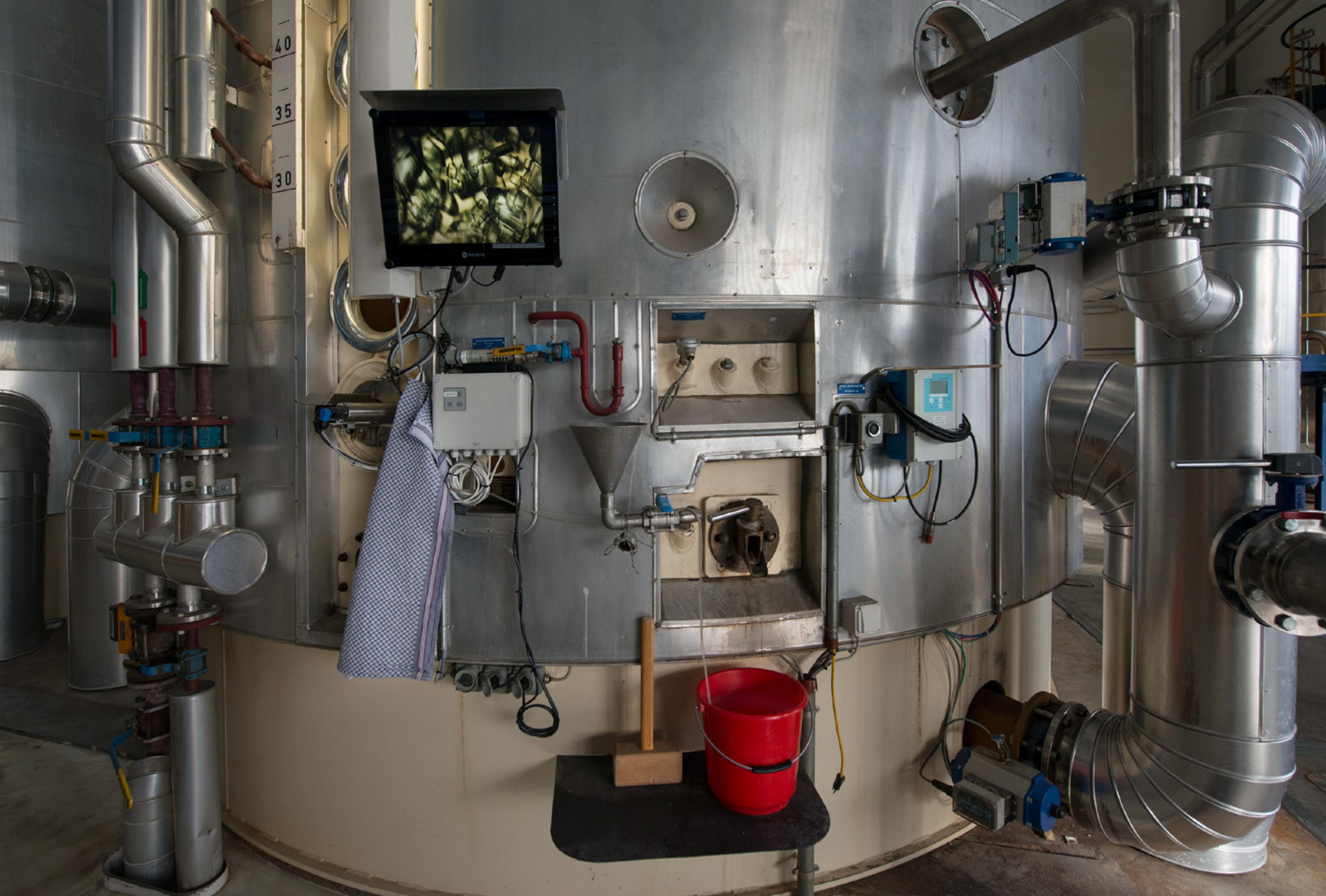




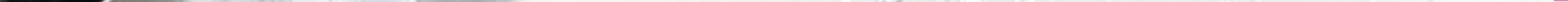


Ce chapitre présente des remarques conclusives et une recommandation, fondées sur les résultats des projets encouragés par le nationales et internationales sur l'alimentation et $l^{\prime}$ environnement, qui ont été faites au cours des dix dernières années.

\section{Conclusions et} recommandation

Le PNR 69 a eu pour ambition de relever les défis posés par le système alimentaire suisse. Il a été conçu pour mentaire durable l'état de santé de la population et la nutrition. Les projets de recherche retenus ont obtenu des resultats substantiels et ont genere des connaissances dans des domaines liês à la production et à la transformation des aliments, aux regimes alimentaires et à la protection de l'environnement.

Ce programme a aussi mis en évidence la complexité du la distribution des produits, la santé de la population et les changements environnementaux émergent comme des problêmatiques sociétales, économiques et sanitaires. Elles sont en plus fortement interdependantes: compte tenu de ces interactions complexes, toute intervention peut avoir des effets inattendus sur d'autres domaines.

La portée des questions centrales du PNR 69 était très vaste, alors que de nombreux projets retenus pour la première phase de recherche portaient sur des champs relativement limités. Ces projets de la première phase leurs domaines. Ils ont aussi permis de développer des recommandations pratiques et d'identifier des lacunes dans les connaissances et leurs applications.

L'étendue du sujet et la complexité des interactions exigent des solutions astucieuses. Il faut viser la création dire un système permettant d'approvisionner à un prix raisonnable des aliments sains, et dont l'impact négatif sur l'environnement est minimal.

Avenir de 1'alimentation: une stratégie est nécessair
La Suisse a élaboré et mis en œuvre des politiques en matière de santé publique, d'environnement et d'agricul ture. Mais rien ne s'apparente à une stratégie portan sur le systeme alimentaire, c'est-à-dire un ensemble inà la production liess aux strategles environnementales, mentaires adéquats. 
La principale recommandation globale du PNR 69 est donc la suivante: nous avons besoin d'une stratégie portant sur le système alimentaire suisse. Cette stratégie doit pour rendre l'alimentation plus saine et la production alimentaire plus durable en Suisse. Elle tiendra compte des éventuels confits dobjectifs entre la production alimentaire, lalimentation saine et dautres parametres so-

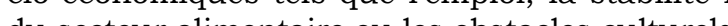
les obstacles culturels.

L'objectif global de cette stratégie permettra une transition harmonieuse du système alimentaire suisse, partant de la situation actuelle et aboutissant à des régimes alimentaires sains et durables.

Un groupe consultatif gouvernemental composé de différents acteurs devrait être installé pour élaborer et mettre en œuvre cette strategie. Il reunirait des repréet de la transformation alimentaires, des production tributeurs, des détaillants, du secteur de la santé publique, ainsi que des représentants des consommatrices et consommateurs.

Les outils et recommandations developpes dans le cadre du PNR 69 seront utilises par cet organe consultatif. Des contacts plus étroits avec lindustrie alimentaire permettront d'inclure d'autres résultats de recherche.

Sur la base des résultats du PNR 69, trois approches ont l'implication des consommatrices et consom transition: (i) les décisions relatives au système alimentaire, de façon à créer une adhésion de la population et à tenir compte de leurs besoins et préférences; (ii) un plan d'action national contre les pertes et le gaspillage alimentaires; et (iii) un amelioration de la production, de la transformation et de la distribution des aliments. La structure de ces recommandations est résumée ci-dessous.

\section{Recommandation}

\section{Developper une stratégie intégrée pour le système}

La Suisse a besoin d'une stratégie portant spécifiquement sur l'avenir du système alimentaire. Cette strategie doit être coherente et integrer simultane-

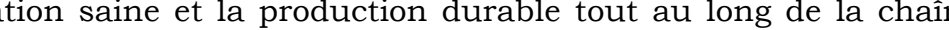

L'objectif général de cette stratégie est d'assurer à la population suisse une alimentation suffisante, saine et produite durablement. En outre, cette stratégie doit identifier et caractériser les outils et les mesures politiques nécessaires pour assurer une transition harmonieuse de la situation actuelle
èmes alimentaires plus intelligents, plus sains et plus durables.

Les résultats du PNR 69 ont mis en évidence certains éléments qui pourraient être utiles à cette stratégie, afin de faire de cette transition une réalité :

1. Les représentants des consommatrices et des consommateurs doivent être etroitement impliqués dans les décisions politiques qui concernent l'ensemble de la chaine alimentaire: il s'agit de mieux tenir compte de leurs besoins préférences, et de renforcer lacceptabilité des decisions. Limplication des reuer au même $n$ veau que les producteurs alimentaires et les industriels.

2. Une grande partie des aliments produits se perd avant leur consommation. Il existe plusieurs méthodes prometteuses pour réduire les pertes et le gaspil-
lage alimentaires. Différentes approches doivent être coordonnées dans un plan d'action national contre les pertes et le gaspillage alimentaires.

3. La production, la transformation et la distribution des aliments doivent être ameliorées. Des technologies innovantes doivent être utilisées à tous les trisurer un approvisionnement en aliments sains de façon durable.

Par ailleurs, la compréhension du système alimentaire doit être élargie. Pour ce faire, la recherche et le développement dans ce domaine doivent être renforce faire, la recherche et le développement dans ce domaine doivent être renfordisciplinaire doit en outre être promue, en collaboration avec des partenaires industriels et académiques.

Impliquer les consommateurs dans l'élaboration

u système alimentaire
Les consommatrices et consommateurs s'orientent de plus en plus vers les produits locaux, respectueux de

Linfluence des consommateurs sur les décisions politiques affectant le système alimentaire est toutefois limitée. Afin d'impliquer toutes les parties concernées, l'administration publique et les instances politiques devraient associer les représentants des consommatrices et des consommateurs aux décisions politiques, au meme titre qu'elles impliquent les producteurs et les industries alisuisse.

Le PNR 69 propose plusieurs moyens d'accroitre l'influence des consommatrices et consommateurs sur les le droit de recours des organisations de protection des consommateurs, conférer aux consommateurs le droit de s'associer à des plaintes collectives, et développe la coopération entre consommateurs, producteurs et industriels.

La prise en compte des intérêts des consommatrices et consommateurs dans le processus politique pourrait mesures d'information sont nécessaires pour que les consommatrices et consommateurs puissent prendre des décisions éclairées et fondées sur les preuves scientifiques existantes. En outre, une stratégie globale renforcerait l'acceptation par les consommateurs des transitions nécessaires au sein du système alimentaire. 
Un plan d'action national

contre les pertes et

Améliorer la production, la transformation et De nombreuses observations montrent qu'une part im-
portante des aliments produits et distribués est perdue pour la consommation humaine. Le gaspillage et les pertes alimentaires ont un impact négatif sur l'environnement dans la mesure où ils sont compensés par une augmentation de la production. Reduire le gaspillage les pertes est donc une approche prometteuse pour accroître la durabilité du système alimentaire.

Dans ce contexte, une modification des critères de qualité des aliments pourrait contribuer à réduire les pertes concerne surtout les standards purement esthétiques, tels que la taille ou la forme de produits comme les légumes ou les pommes de terre.

Une autre approche consiste à promouvoir et à appliquer des pratiques innovantes pour la conservation de aliments, ainsi que de nouvelles methodes de datage des aliments. En effet, les consommatrices et consommatemps après leur date de péremption. Des campeu de d'information sur la manière d'interpréter correctement les dates d'expiration devraient être envisagées. En outre, de nouveaux types de labels, tels que ceux proposés dans le cadre du projet "Nano conservation" ", pourraient etre developpes pour certains aliments, afin de remplacer les dates de péremption existantes.

Les premières étapes vers un plan d'action national sur les pertes et le gaspillage alimentaires ont eté franchies. postulat qui charge le Conseil fédéral d'élaborer un tel plan d'action ${ }^{26}$.

Ce plan recensera les différentes actions déjà mises en œuvre en Suisse, et devra en évaluer l'impact. Si nécessaire, il proposera des actions supplementaires à différents niveaux, afin de garantir l'atteinte de son objectif: une diminution de moitié du gaspillage des aliments comestibles aux niveaux de la vente au détail et de la mentaires dans l'agriculture le commerce et l'industrie Parlement un indicateur permettant de suivre régulièrement l'evolution de la reduction des pertes et du gaspillage dans les différents secteurs concernés.

Des solutions pour une production, une transformation et une distribution plus durables des aliments, favori-

La bonne nouvelle émanant des projets du PNR 69 est qu'il existe des mesures contribuant simultanément une production alimentaire durable et à une alimentation saine. Par exemple, la sante des consommateurs et mation de viande et de sucre était réduite, comme

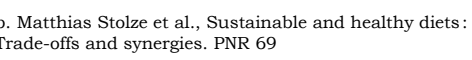

Développer une lign

développement

transdisciplinaire dédiée lindique le projet "Recommandations pour une alimentation saine et durable "

Différents projets du PNR 69 ont proposé des solutions pertinentes pour une alimentation plus saine et de melleures conditions pour une production durable. Ces solution peuvent être réalisées à grande échelle à très court terme.

Le projet transversal "Recommandations pour une alimentation saine et durable $"^{\mathrm{b}}$ montre qu'il existe auss et une production alimentaire durable. Pour améliore le système alimentaire suisse, la chaine alimentaire doit donc être considérée dans son ensemble et tous les acteurs de cette chaine doivent être impliqués.

Lalimentation, la santé et l'environnement font l'obje de nombreuses recherches à linternational. De noupermettent d'identifier les divers mécanismes biomédicaux, épidémiologiques et environnementaux qui lient l'alimentation à la santé et à l'environnement.

Le rapport publié en 2019 par le World Resource Institute ${ }^{2 t}$ insiste sur la nécessite de la R\&D pour l'avenir mondial de lalimentation. Le rapport souligne que des recherches supplementaires sont nécessaires pour surmonter les nombreux obstacles à la réalisation d'un avenir durable en mácessité d'un financement adéquat pour poursuivre la recherche sur les pistes les plus prometteuses Pour répondre à ces besoins, il s'agira d'augmenter significativement la quantité de financements par rapport à ce qui est actuellement disponible, de consacre plus d'efforts à l'application directe de la recherche et de viser des percees technologiques importantes. Les efforts de la R\&D devront porter en particulier vers laccroissement de la productivité, la réforme des infrastructures et la contribution des services de protection de nvironnement.

Le PNR 69 est une réponse de la Suisse à cette déclaration. Les résultats obtenus par les groupes de recherche reflètent la force de la communauté scientifique suisse
dans les domaines de la nutrition, de l'agriculture et de l'environnement. La contribution des chercheuses et chercheurs consistait a développer des connaissances scientifiques fondees sur des faits, ainsi que des solutions pratiques visant à relever des défis concrets du

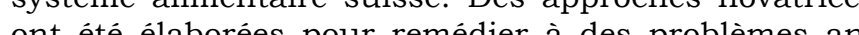
ont ete elaborees pour remédier a des problemes anont abouti à des résultats pertinents dans différents domaines de la chaîne alimentaire (tel que résumés dan les chapitres 2,3 et 4 ci-dessus). La plupart de ces résultats de recherche ont été publiés dans des revues spécialisées (voir liste en annexe 1). 
La Suisse dispose donc de solides compétences, tant dans le secteur public que dans le secteur privé. La pluniveau et jouissent d'une reconnaissance internationale en Europe comme dans le monde. La Suisse bénéficie, en particulier, d'une capacité demontree dans le développement de nouveaux produits et la mise en ouvre de stratégies basees sur la science fondamentale dans le secteu alimentaire prive. Ce niveau eleve de R\&D deviait etre

Le PNR 69 souligne la nécessité d'une réflexion intégrée et d'une collaboration de tous les acteurs de la chaîne alimentaire. Peu d'organes collaborent sur la mise en place de stratégies portant sur l'ensemble du système alimentaire. Et il existe encore moins d'organes réunissant des scientifiques, des representants industriels et les administrations publiques. Dans le cadre du PNR 69, on peut d'ailleurs observer que seuls quelques groupes de recherche ont soumis des projets interdisciplinaires ponts entre diveres perspectives du systeme alimentaire devrait donc être fortement encouragée.

Dans ce contexte, les collaborations entre la recherche industrielle et la recherche academique devraient aussi être renforcées, en sinspirant peut-être des modèles de pharmaceutique et la recherche académique médicale.

Une façon de susciter la recherche en ce sens pourrait étre de creer un Pole de recherche national (PRN). pour soutenir sur le long terme des projets de recherche sur des thèmes d'importance stratégique pour l'avenir de la science, de l'économie et de la société.

Une autre possibilité est la nouvelle structure d'encouragement qui reunit les chercheurs soutenus par le FNS et les parties prenantes pour transposer les résultats de la recherche en applications pratiques. Ce programme tencourt par le FNS et Innosuisse - l'Agence suisse pour l'encouragement de l'innovation.

D'autre part, les instances suisses (académiques, gouvernementales et industrielles) devraient être encouragées à développer et à maintenir une collaboration étroite avec les entités internationales actives aux niveaux européen et/ou mondial. Il s'agit en particulier
d'insister sur la collaboration avec l'Union européenne, par exemple dans le cadre de Joint Programming A Healthy Diet for a Healthy Life (HDHL).
Afin de quantifier la réussite des efforts décrits ci-dessus et de déterminer la nécessité d'actions supplémentaires, il convient de mettre en place un système de monitorage l'évolution des parentaire suisse. Il permettra de suive taires en réponse à des interventions spécifiques. Il es important de noter que la Suisse affiche un retard par rapport à d'autres pays. la premiere étude nationale sur les régimes alimentaires n'a été réalisée qu'en 2013.

Dans le même ordre d'idées, la recherche académique devrait être encouragée à développer des approches expérimentales ou quasi-expérimentales pour évaluer l'efsi-expérimental a été utilisé pour l'introduction du labe Nutri-Score en France ${ }^{28}$.

En somme, il est essentiel d'identifier et de réduire les lacunes dans les connaissances scientifiques pour offrir une expécise specials. que d'autres secteurs fait l'objet d'un nombre croissant de prescriptions, d'avis et de conseils venant d'acteurs en tous genres. Une hiérarchisation entre les preuves scientifiques et l'opinion publique fait défaut. Pour cette raison, des recommandations claires et bien raisonnées sur ce qui constitue une alimentation saine et sur la maniere de promouvoir une production alimentaire du-

Toujours dans cette perspective, le PNR 69 souligne la sectorielle du système alinentaire suisse pour antiorsimultanément la santé des personnes et la durabilité de l'environnement. 


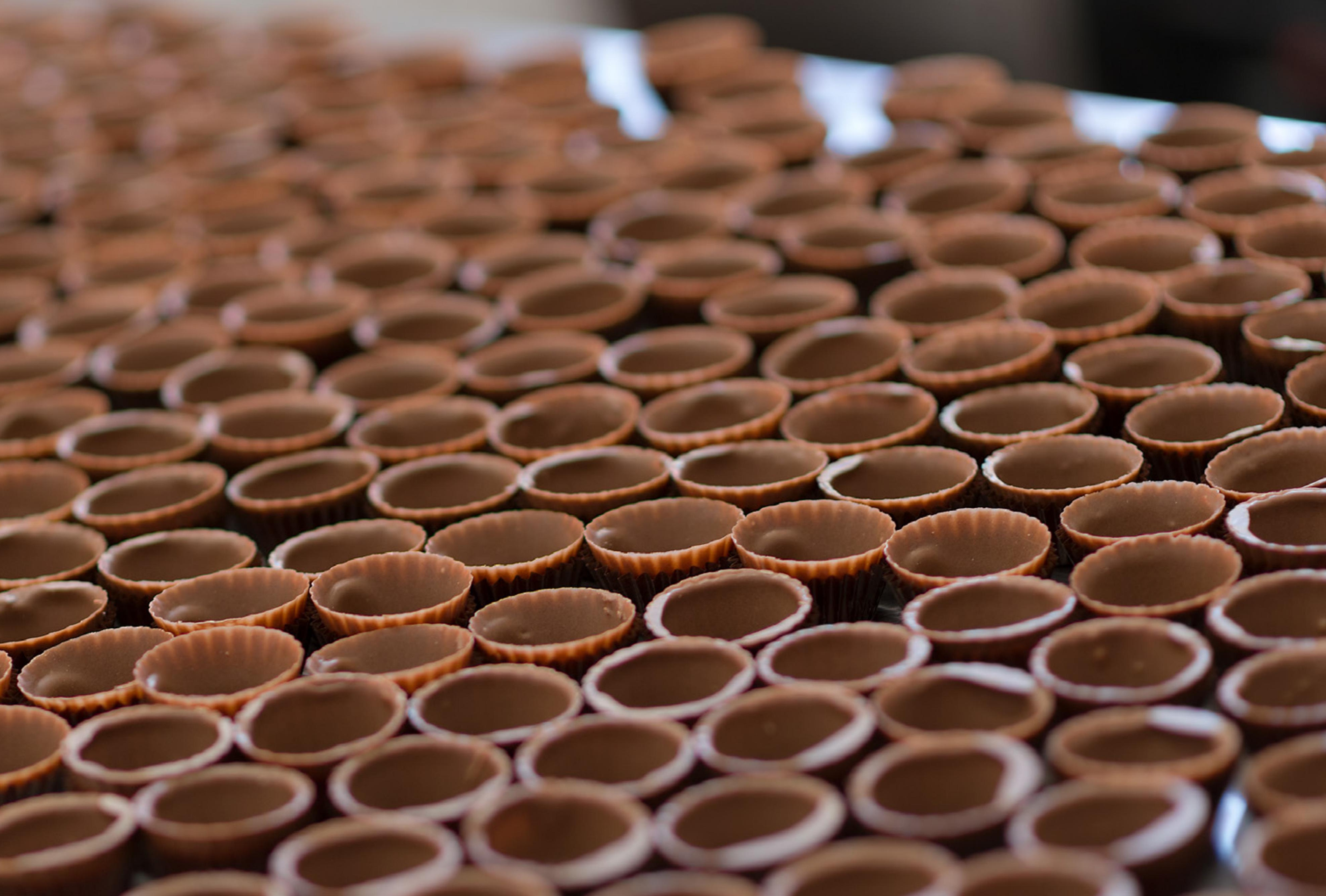




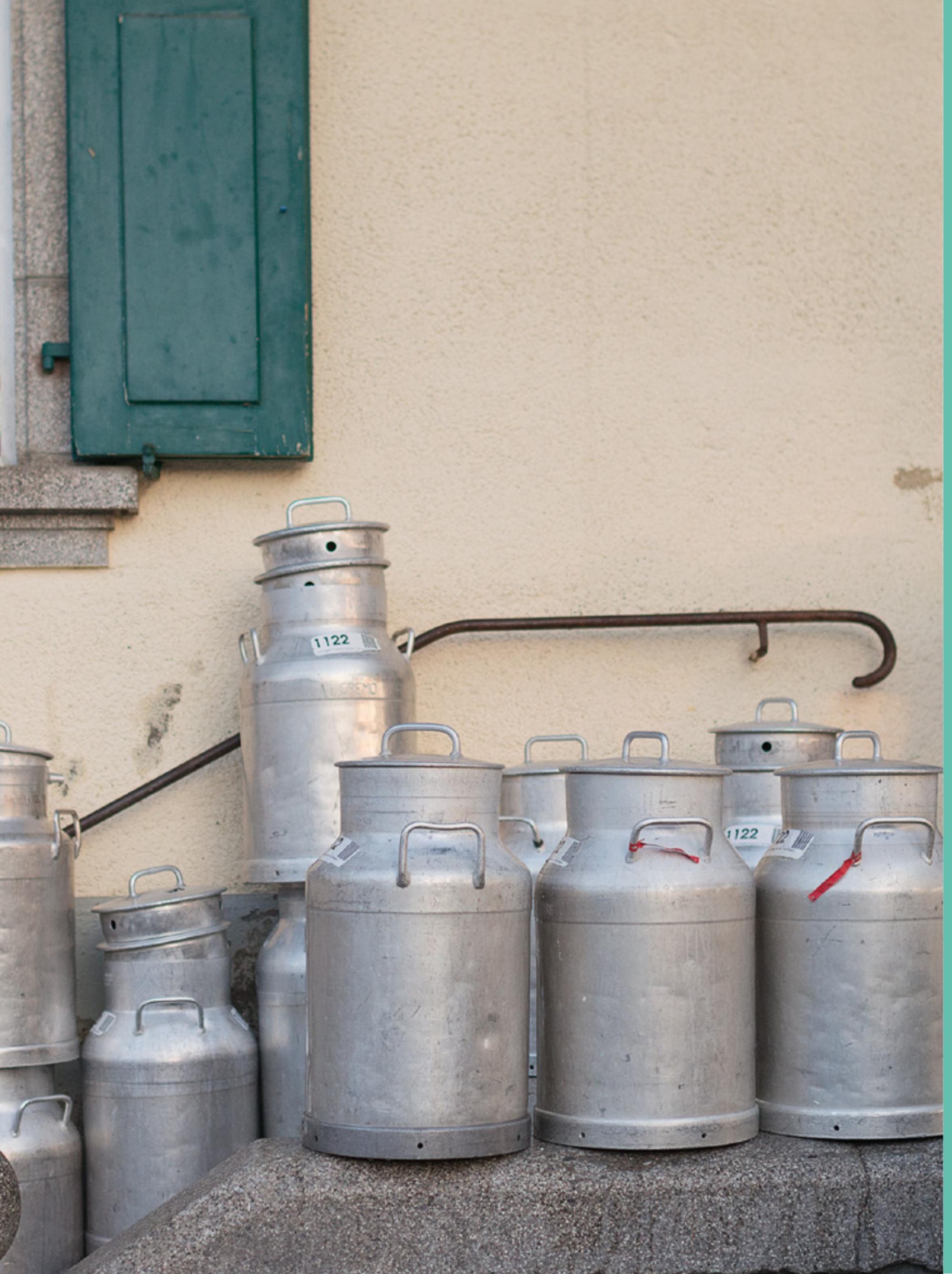


Selon la Loi fédérale sur les denrées alimentaires et les objets usuels, on entend par denrées alimentaires "l'ensemble des substances ou des produits transformés, partiellement transformes ou non transformés qui son destinès à être ingêrés ou dont on peut raisonnablement s'attendre à ce qu'ils soient ingérés par l'être humain ${ }^{29}$.

\section{Système alimentaire}

Le système alimentaire comprend tous les éléments et activités liés à la production, au transport, à la transformation, à lemballage, au stockage, à la vente, à la consommation, aux pertes et au gaspillage $e^{3 / 30}$.

\section{Régimes alimentaires sains}

Les régimes alimentaires sains se caractérisent par un apport calorique approprié et consistent en une diversité d'aliments d'origine végétale, de faibles quantités d'aliments d'origine animale, des gras insaturés plutôt que saturés et de petites quantités de grains raffinés, d'ali-
ments hautement transformés et de sucres ajoutés ments hautement transformés et de sucres ajoutes

\section{Santé publique}

La santé publique est l'art et la science permettant d'élaborer et de mettre en ouvre des réponses appropriées aux besoins de la population en matière de santé.

\section{Développement durable}

Selon l'Organisation des Nations Unies pour l'alimentation et l'agriculture (FAO), le développement durable consiste à "aménager et conserver les ressources naturelles et orienter les changements techniques et institutions actuelles et futures. Il s'agit pour cela de conserver les terres, les eaux et le patrimoine zoogénétique et phytogénetique et dutiliser des moyens sans danger pour l'environnement, techniquement bien adaptés, économiquement viables et socialement acceptables $n^{32}$.

\section{Gaspillage alimentaire}

Selon la FAO, le gaspillage alimentaire désigne une mise au rebut ou une utilisation alternative (non alimentaire) d'aliments qui sont sûrs et nutritifs pour la consommation humaine ${ }^{33}$. 


\section{Perte alimentaire}

Selon la FAO, la perte alimentaire désigne toute perte d'aliments survenant dans la chaîne alimentaire, entre le producteur et le marchée ${ }^{33}$.

\section{Sécurité alimentaire}

La sécurité alimentaire désigne une situation dans laLa selle tous les êtres humains unt accès physique, social et économique à une alimentation suffisante, sûre et nutritive qui répond à leurs besoins et est conforme à leurs préférences alimentaires ${ }^{3}$.

\section{Transformation des aliments}

La FAO définit la transformation des aliments comme tout changement apporté à un aliment pour modifier sa
qualité alimentaire ou sa durée de conservation. La clasformation comme clé de classification, soit (i) aliment non-transformés ou peu transformés, (ii) ingrédients culinaires transformés, (iii) aliments transformés, (iv) aliments ultra-transformés. 
2. Lang Tim, Barling David, Caraher Martin, Food Policy: Integrating Health, Environment and Society, Oxford, OUP, 2009.

3. United Nations Environment Programme [UNEP], International Resource Panel, Global Resources Outloo 2019:

4. Office fédéral de la statistique [OFS], Agriculture et alimentation - Statistique de poche 2019.

5. Nations Unies, Département des affaires économiques et sociales, Actualites, La population mondiale devrait atteindre 9,8 milliards en 2050 et 11,2 milliards en 2011 selon l'ONU, 2017.

6. Organisation des Nations Unies pour l'alimentation et l'agriculture [FAO], Les défis de l'agriculture à l'horizon 2050, 2009.

7. Organisation des Nations Unies pour l'alimentation et l'agriculture [FAO], Département du développement économique et social, L'Etat de la sécurité alimentaire et de la nutrition dans le monde, 2019.

8. McMichael Anthony J, Powles John W, Butler Colin D, Uauy Ricardo, Food, livestock production, energy, climat

9. Organisation des Nations Unies pour l'alimentation et l'agriculture [FAO], Graisses et acides gras dans la nutrition humaine - Rapport d'une consultation d'experts, 2010.

10. Organisation des Nations Unies pour l'alimentation et l'agriculture [ $\mathrm{K}$ (O), Pertes et gaspillages alimentaires dans le monde - Ampleur, causes et prévention, 2011.

11. Office fédéral de l'environnement [OFEV], Déchets alimentaires, 2018.

12. Mengheri Elena, Diet Quality is Associated with Microbial Diversity and Host Health, The Journal of
Nutrition, Vol. 149 Issue 9, September 2019, 1489-1490.

13. Office fédéral de la santé publique [OFSP], Cost of obesity in Switzerland in 2012, 2014.

14. Société suisse de nutrition, Communiqué de presse, Des études universitaires le confirment: Une restauration du personnel de qualite augmente la

15. McLean Erin et al., Worldwide prevalence of anaemia, WHO Vitamin and Mineral Nutrition Information System, 1993-2005, Public Health Nutrition, Vol. 12, Issue 4 2009, 444-454.

16. Cochrane UK, Vitamin D supplements in pregnancy: what's the latest evidence?, 2019. 
17. ETH Zurich, World Food System Center, Foresight Study: Research for a Sustainable Swiss Food System, 2015.

18. Office fédéral de l'environnement [OFEV], Objectifs environnementaux pour l'agriculture, 2016.

19. Conseil fédéral, OAS 913.1, Ordonnance sur les améliorations structurelles dans l'agriculture, 2019.

20. Proviande, Statistique, Consommation de viande 2017 en Suisse, 28.03.2018

21. Nations Unies, Programme de développement durable à l'horizon 2030, 2015 .

22. Commission européenne, Communiqué de presse, Prévenir le gaspillage alimentaire, promouvoir l'économie circulaire. la Commission adopte une methodologie com06.05.2019.

23. Office fédéral de la santé publique [OFSP], Stratégies nationales en matière de santê, 2018.

24. Office fédéral de la sécurité alimentaire et des affaires vetérinaires [OSAV], Stratégie suisse de nutrition 2017-2024.

25. Commission européenne, EU Framework for National Initiatives on Selected Nutritents, Added Sugars Annex,

26. Postulat 18.3829 de la conseillère nationale Isabelle Chevalley, Plan d'action contre le gaspillage alimentaire, 2018.

27. World Resources Institute. Creating a sustainable food future. A Menu of Solutions to Feed Nearly 10 Billion People by 2050. Final Report. Washington, DC: World
Resources Institute, 2019.

28. Egnell Manon et al. Font-of-Pack Labeling and the . Health, 109, no. 8, August 2019, 1122-1129.

29. Loi fédérale sur les denrées alimentaires et les objets usuels (Loi sur les denrées alimentaires, LDAI), 2013.

30. Willett Walter et al., Food in the Anthropocene: the EAT-Lancet Commission on healthy diets from sus tainable food systems, Lanc

31.Monteiro Carlos A et al., NOVA. The star shines bright .

32. Organisation des Nations Unies pour l'alimentation et l'agriculture [FAO], Evaluation de la durabilité des systèmes agricoles et alimentaires (SAFA), 2014.

33. Organisation des Nations Unies pour l'alimentation et limentaire, 2015. 
Annexe 1

sélectionnés scientifiques financés par le PNR 69

\section{Annexes}

2019 The Fate of $\mathrm{Zn}$ in Agricultural Soils: A Stable Isotope Ap-
proach to Anthropogenic Impact, Soil Formation, and Soil-Plant Cycling.

Imseng M, Wiggenhauser M, Müller M, Keller A, Frossard E, Wilcke W, Bigalke

Environ Sci Technol. 2019 Apr 16;53(8):4140-4149. doi: $10.1021 /$ acs.est.8b03675. Epub 2019 Apr 5 .

Towards an understanding of the $\mathrm{Cd}$ isotope fractionation during transfer from the soil to the cereal grain. Imseng M, Wiggenhauser M, Keller A, Müller M, Rehkämper M, Murphy K, Kreissig K, Frossard E, Wilcke W, Bigalke $\mathrm{M}$

Environ Pollut. 2019 Jan $244: 834-844$

doi: 10.1016/j.envpol.2018.09.149. Epub 2018 Oct 12 . PMID: 30390457

Cultural Differences in Diet and Determinants of Diet Quality in Switzerland: Results from the National Nutrition Survey menuCH. Pestoni G, Krieger JP, Sych JM, Faeh D, Rohrmann S. Nutrients. 2019 Jan 9;11(1). pii: E126. doi: $10.3390 /$ nu11010126. PMID: 30634520

RE-AIM evaluation of a one-year trial of a combined educational and environmental workplace intervention to Ber salt intake in Switzenland.

X. Prev Med Strazzullo P, Luta X. PMID: 31516815

Using isotopes to trace freshly applied cadmium through mineral phosphorus fertilization in soil-fertilizer-plan systems.

Wiggenhauser M, Bigalke M, Imseng M, Keller A, Rehossard E

doi: 10.1016/j.scitotenv.2018.08.127. Epub 2018 Aug 14 PMID: 30138877

\section{8}

Dietary Patterns Are Associated with Cardiovascula and Cancer Mortality among Swiss Adults in a Census-Linked Cohort.
Krieger JP, Cabase

, Cabaset S, Pestoni G, Rohrmann S, Faeh D Nutrients. 2018 Mar $7 \cdot 10(3)$. pii : 313

doi: $10.3390 /$ nu 10030313 .

PMID: 29518908 

Dietary Patterns and Their Sociodemographic and Lifetional Nutrition Survey menuCH.

Krieger JP, Pestoni G, Cabaset S, Brombach C, Sych J, Schader C, Faeh D, Rohrmann S.

Nutrients. 2018 Dec 29;11(1). pii: E62.

doi: $10.3390 /$ nu 11

(3)

Enhancing enterocyte fatty acid oxidation in mice affects glycemic control depending on dietary fat.

Ramachandran D, Clara R, Fedele S, Michel L, Burkard J, Kaufman S, Diaz AA, Weissfeld N, De Bock K, PripBuus C, Langhans W, Mansouri A.

Sci Rep. 2018 Jul $17: 8(1): 10818$.

doi: $10.1038 / \mathrm{s} 41598-018-29139-6$

PMID: 30018405

Prevalence and determinants of vitamin D deficiency in the third trimester of pregnancy: a multicntre study in

Krieger JP, Cabaset S, Canonica C, Christoffel L, Richard A, Mann S, Lötscher KQ. PMID: 29318983

Exploiting multicompartment effects in triple-ech steady-state T2 mapping for fat fraction quantification.

Liu D, Steingoetter A, Curcic J, Kozerke S.

doi: $10.1002 / \mathrm{mrm} 26680$. Epub 2017 Ma 25.

PMID: 28342191

Fate of Cd in Agricultural Soils: A Stable Isotope Approach to Anthropogenic Impact, Soil Formation, and Soil-Plant Cycling.

Imseng M, Wiggenhauser M, Keller A, Müller M, Rehkämper M, Murphy K, Kreissig K, Frossard E, Wilcke W, Bigalke $\mathrm{M}$

Environ Sci Technol. 2018 Feb 20;52(4):1919-1928.

PMID: 29308892

Tailoring Emulsions for Controlled Lipid Release: Establishing in vitro-in Vivo Correlation for Digestion of Lipids. Scheuble N, Schaffner J, Schumacher M, Windhab EJ, Liu D, Parker H, Steingoetter A, Fischer

ACS Appl Mater Interfaces. 2018 May 30;10(21):17571-

doi: 10.1021/acsami.8b02637. Epub 2018 May 16. PMID : 29708724

Cutting through conflicting prescriptions: How guidelines inform "healthy and sustainable " diets in Switzerland.

Godin L, Sahakian M.

Appetite. 2018 Nov 1;130:123-133

doi: 10.1016/j.appet.2018.08.004. Epub 2018 Aug 4.

PMID: 30086323
Clustering of Pan- and Core-genome of Lactobacillus Inglin RC, Meile L, Stevens MJA.

BMC Genomics. 2018 Apr 24;19(1):284.

doi: $10.1186 / \mathrm{s} 12864-018-4601-5$.

PMID: 29690879

Just a subtle difference? Findings from a systematic review on definitions of nutrition literacy and food literacy Health Promot Int. 2018 Jun 1,33(3):378-389.

doi: $10.1093 /$ heapro/daw084. Review.

PMID : 27803197

A short food literacy questionnaire (SFLQ) for adults Findings from a Swiss validation study.

Grea Krause C, Beer-Borst S, Sommerhalder K, Hayoz S, Abel T.

Appetite. 2018 Jan 1;120:275-280

doi: 10.1016/j.appet.2017.08.039. Epub 2017 Sep 11. PMID: 28912107

New horizons for future research - Critical issues to consider for maximizing research excellence and impact. Langhans W, Adan R, Arnold M, Banks WA, Card JP, Dailey MJ, Daniels D, de Kloet AD, de Lartigue G, Dickson S, Fedele S, Grill HJ, Jansson JO, Kaufman S, Kolar G, Krause E, Lee SJ, Le Foll C, Levin BE, Lutz TA, Mansouri A, Moran TH, Pacheco-Lopez G, Ramachandran D, Raybould H, Rinaman L, Samson WK, Sanchez-Watts G, KL Templeton B, Trap, S, Tso P, Watts AC, Weissfeld N, Williams D, Wolfum C, Yosten G, Woods SC.

doi: 10.1016/j.molmet. 2018.05.007. Epub 2018 May 12. No abstract available.

Zinc isotope fractionation during grain filling of whea and a comparison of zinc and cadmium isotope ratios in identical soil-plant systems.

Imseng M, Keller A, Archer New Phytol. 2018 Jul E.

doi: 10.1111/nph.15146. Epub 2018 Apr 26.

Oleoylethanolamide-induced anorexia in rats is associated with locomotor impairment

Fedele S, Arnold M, Krieger JP, Wolfstädter B, Meyer U, Langhans $\mathrm{W}$, Mansouri A.

doi: 10.14814 phy2 13517.

PMID: 29388342 
Study design and baseline characteristics of a combined educational and environmental intervention trial to lower sodium intake in Swiss employees.

Beer-Borst S, Luta X, Hayoz S, Sommerhalder K, Krause CG, Eisenblätter J, Jent S, Siegenthaler S, Aubert R, Haldimann M, Strazzullo P.

BMC Public Health. 2018 Apr 2;18(1):421.

doi: $10.1186 / \mathrm{s} 12889-$

Responses of Oat Grains to Fusarium poae and F. langsethiae Infections and Mycotoxin Contaminations.

Martin C, Schöneberg T, Vogelgsang S, Mendes Ferreira CS, Morisoll
Mascher F.

Toxins (Basel). 2018 Jan 20;10(1). pii: E47.

doi: $10.3390 /$ toxins 1001004

PMID: 29361693

The relationship of health/food literacy and salt awareness to daily sodium and potassium intake among workplace population in Switzerland.

Luta X1, Hayoz S1, Gréa Krause C1,

Nutr Metab Cardiovasc Dis, 2018 Mar.28(3) :270-277. doi: 10.1016/j.numecd.2017.10.028. Epub 2017 Nov 13. PMID: 29310971

\section{7}

Amyloid fibril systems reduce, stabilize and deliver bioavailable nan

Shen Y, Posavec L, Bolisetty S, Hilty FM, Nyström G, Kohlbrecher J, Hilbe M, Rossi A, Baumgartner J, Zimmermann MB, Mezzenga R.

Nat Nanotechnol. 2017 Jul;12(7):642-647.

doi: 10.1038/nnano.2017.58. Epub 2017 Apr 24.

A nudge in a healthier direction: How environmental the pursue their weight-control goal.

Stämpfli AE, Stöckli S, Brunner TA.

doi: 10.1017/ Mar 1;110:94-102. PMID: 27915080

Socioeconomic Determinants of Sodium Intake in Adult Populations of High-Income Countries: A Systematic Review and Meta-Analysis.

Petrovic D, Marques-Vidal P, Am J Public Health. 2017 A

doi: 10.2105/AJPH.2016.303629. Epub 2017 Feb 16. Review.

Fifteen-year trends in the prevalence of barriers to healthy eating in a high-income country.

C, Marques-Vidal P.
Am J Clin Nutr. 2017 Mar;105(3):660-668 doi: 10.3945/ajcn.116.143719. Epub 2017 Jan 25. PMID: 28122785

Food loss reduction from an environmental, socio-economic and consumer perspective - The case of the Swiss potato market.

Willersinn C, Mouron P, Mack G, Siegrist M.

Waste Manag. 2017 Jan,59:451-464.

2016 Oct 15

Ion-Induced Hydrogel Formation and Nematic Ordering of Nanocrystalline Cellulose Suspensions.

Bertsch P, Isabettini S, Fischer P.

Biomacromolecules. 2017 Dec 11;18(12):4060-4066. doi: 10.1021/acs.biomac.7b01119. Epub 2017 Oct 20. PMID: 2902833

Metabolic Adaptation of the Small Intestine to Short- and Medium-Term High-Fat Diet Exposure.

Fedele $S$ Krieger JP, Langhans W, Mansouri A.

J Cell Physiol. 2017 Jan;232(1):167-75. doi: $10.1002 /$ jcp.25402. Epub 2016 Apr 28. PMID: 27061934

Intestinal SIRT3 overexpression in mice improves whole body glucose homeostasis independent of body weight. Ramachandran D, Clara R, Fedele S, Hu J, Lackzo E, Huang JY, Verdin E, Langhans W, Mansour A.

doi: 10.1016/j.molmet.2017.07.009. Epub 2017 Jul 18.

PMID: 29031725

Gastric and Postgastric Processing of 13C Markers Renders the $13 \mathrm{C}$ Breath Test an Inappropriate Measurement Method for the Gastric Emptying of Lipid Emulsions in

Parker HL, Liu D, Curcic J, Ebert MO, Schwizer W, Fried M, Steingoetter A.

ul: 147(7):1258-1266

doi: 10.3945/jn.117.248765. Epub 2017 May 31.

PMID: 28566523

Accelerating MRI fat quantification using a signal model-based dictionary to assess gastric fat volume and distribution of fat fraction.

Liu D, Steingoetter A, Parker HL, Curcic J, Kozerke S.

. PMID: 27867052

Microfluidic Technique for the Simultaneous Quantification of Emulsion Instabilities and Lipid Digestion Kinetics. Scheuble N, Iles A, Wootton RCR, Windhab EJ, Fische P, Elvira KS.

Anal Chem. 2017 Sep $5 ; 89(17): 9116-9123$ doi: 10.1021/acs.analchem.7b01853. Epub 2017 Aug 18 . PMID: 28770989 
Highly Selective Volatile Organic Compounds Breath Analysis Using a Broadly-Tunable Vertical-External-Cavity Surface-Emitting Laser.

Tuzson B, Jágerská J, Looser H, Graf M, Felder F, Fill M, Tappy L, Emmenegger L.

Anal Chem. 2017 Jun 20;89(12):6377-6383. doi: $10.1021 /$ acs.analchem.6b04511. Epub 2017 May 26.
PMID: 28514136

Complete and Assembled Genome Sequence of Lactobacillus plantarum RI-113 Isolated from Salami.

Genome Announc. 2017 Apr 20 5(16). pii: e00183-17. doi: 10.1128/genomeA.00183-17.

PMID: 28428294

Complete and Assembled Genome Sequence of Vagococcus teuberi DSM 21459T, a Novel Species Isolated from Fermented Cow Milk in Mali.

Genome Announc. 2017 Jan 26:5(4). pii: e01514-16.

doi: 10.1128/genomeA.01514-16.

PMID: 28126942

Draft Genome Sequences of 43 Lactobacillus Strains from the Species L. curvatus, L. fermentum, L. paracasei, L. plantarum, L. rhamnosus, and L. sakei, Isolated from Food Products.

Inglin RC, Meile L, Stevens MJA

Genome Announc. 2017 Jul 27;5(30). pii: e00632-17. PMID: 28751390

Prevalence of Vitamin D Deficiency and Its Associations with Skin Color in Pregnant Women in the First Trimester in a Sample from Switzerland.

Richard A, Rohrmann S, Quack Lotscher KC.

Nutrients. 2017 Mar 10;9(3). pii: E260.

doi: $10.3390 /$ nu 9030260

PMID: 28287422

\section{6}

Barriers to healthy eating in Switzerland: A nationwide study.

de Mestral C, Stringhini S, Marques-Vidal P.

Clin Nutr. 2016 Dec;35(6):1490-1498. doi: $10.1016 / \mathrm{j}$ clnu.2016.04.004. Epub 2016 Apr 7.

PMID: 27091772

Tracing and inhibiting growth of Staphylococcus aureus in barbecue cheese production after product recall.

J Dairy Sci. 2016 May;99(5):3345-

doi : 10.3168/jds. 2015-10689. Epub 2016 Mar 9. PMID: 26971157
RE-AIM evaluation of a one-year trial of a combined educationa lower salt Sequence Variability in Staphylococcal Enterotoxin Genes seb, sec, and sed.

Johler S, Sihto HM, Macori G, Stephan R. Toxins (Basel). 2016 Jun 1;8(6). pii: E169. doi: $10.3390 /$ toxins 80601

An (un)healthy poster: When environmental cues affect consumers' food choices at vending machines.

Appetite. 2016 Jan 1;96:368-374

doi: 10.1016/j.appet.2015.09.034. Epub 2015 Oct 22. PMID: 26431685

Mechanically Enhanced Liquid Interfaces at Human Body Temperature Using Thermosensitive Methylated Nanocrystalline Cellulose.

Perster S, Adamcik J, Mezzenga R, Langmuir 2016 Feb $9 ; 32$

doi: 10.1021/acs.langmuir.5b04231. Epub 2016 Jan 27. PMID: 26779953

Risk factors for oral antimicrobial consumption in Swiss fattening pig farms - a case-control study.

Arnold C, Schupbach-Regula G, Hirsiger P, Malik J, Scheer P, Sidler X, Spring P, Peter-Egli J, Harisberger M.

doi: 10.1186/s40813-016-0024-3, eCollection 2016.

28405431

Fusarium and mycotoxin spectra in Swiss barley are affected by various cropping techniques.

Schöneberg T, Martin C, Wettstein FE, Bucheli TD, Mascher F, Bertossa M, Musa T, Keller B, Vogelgsang S. Food Addit Contam Part A Chem Anal Control Expo Ris PMID: 2749181

Blocking Gastric Lipase Adsorption and Displacement Processes with Viscoelastic Biopolymer Adsorption LayScheuble N, Lussi M, Geue T, Carrière F, Fischer P. Biomacromolecules. 2016 Oct 10;17(10):3328-3337. Epub 2016 Sep 27.

Emulsion Stability Modulates Gastric Secretion and It Mixing with Emulsified Fat in Healthy Adults in a RandMagnetic Resonance Imaging Study.

Per HL, Curcic J, Kozerke S, Steingoetter A. 2016 Oct;146(10):2158-2164. Epub 2016 Sep 7 PMID: 27605407 
The visualisation and quantification of human gastrointestinal fat distribution with MRI: a randomised study in healthy subjects.

Liu D, Parker HL, Curcic J, Schwizer W, Fried M, Kozerke S, Steingoetter A.

Br J Nutr. 2016 Mar 14;115(5) :903-12.

doi: 10.1017/S0007114515005188. Epub 2016 Jan 19. PMID: 26782705

Scanning-SAXS of microfluidic flows: nanostructural mapping of soft matter.

, $P$, Liebi M.

Lab Chip. 2016 Oct $5 ; 16(20): 4028-4035$

PMID: 27713983

\section{5}

Further evidence for staphylococcal food poisoning outbreaks caused by egc-encoded enterotoxins. Toxins (Basel). 2015 Mar $20 ; 7$

;7(3):997-1004

doi: $10.3390 /$ toxins7030997.

PMID: 25802973

Outbreak of staphylococcal food poisoning among children and staff at a Swiss boarding school due to soft cheese made from raw milk.

Jummerion J, Robert L, J Dairy Sci. 2015 May:98(5):294.

jds.2014-9123. Epub 2015 Feb 26

Complete and Assembled Genome Sequence of Staphylococcus aureus RKI4, a Food-Poisoning Strain Exhibiting a Novel S. aureus Pathogenicity Island Carrying seb.

Stevens MJ, Stephan R, Johler S.

Gii: e00769-15.

PMID: 26139727

Temporal expression of the staphylococcal enterotoxin

gene under $\mathrm{NaCl}$ stress conditions.

Sihto HM, Tasara T, Stephan R, Johler S.

FEMS Microbiol Lett. 2015 Mar,362(6). pii. fnv024.

doi: 10.1093/femsle/fnv024. Epub 2015 Feb 16.

Quantity and quality of food losses along the Swiss potato supply chain: Stepwise investigation and the influence Willersinn $C$, Mack $\mathrm{C}$, losses.

Waste Manag. 2015 Dec:46:120, Keiser A, Siegrist M.

doi: 10.1016/j.wasman.2015.08.033. Epub 2015 Sep 2. PMID: 26341828
Imaging gastric structuring of lipid emulsions and its effect on gastrointestinal function: a randomized trial in healthy subjects.

Steingoetter A, Radovic T, Buetikofer S, Curcic J, Menne D, Fried M, Schwizer W, Wooster TJ

doi: 10.3945/ajcn.114.100263. Epub 2015 Feb 25.

PMID: 25833970

New concepts to fight oxidative stress: nanosized three-dimensional supramolecular antioxidant assemblies Expert Opin Drug Deliv . 2015 12 (9) $: 1527-45$.

doi: 10.1517/17425247.2015.1036738. Epub 2015 Apr 16. Review.

\section{PMID: 25882382}

High-throughput screening assays for antibacterial and antifungal activities of Lactobacillus species.

.

doi: 10.1016/j.mimet.2015.04.011. Epub 2015 Apr 30.

\section{4}

Validation of reference genes for normalization of qPCR mRNA expression levels in Staphylococcus aureus exposed to osmotic and lactic acid stress conditions enSihto HM Tas T S Tephan R, Johler S. FEMS Mich The doi: 10.1111/1574-6968.12491. Epub 2014 Jun 19 PMID: 24893820

Completed egoism and intended altruism boost healthy food choices.

Weibel C, Messner C, Brügger A.

Appetite. 2014 Jun, $77: 3845$

.appet.2014.02 010. Epub 2014 Feb 24

Inheritance of porcine receptors for enterotoxigenic Escherichia coli with fimbriae F4ad and their relation to other F4 receptors.

Bratus A, Vögeli P, Neuenschwander S.

Animal. 2014 Jun;8(6):859-66.

doi: 10.1017/S1751731114000779. Epub 2014 Apr 11

"Active surfaces" formed by immobilization of enzymes on solid-supported polymer membranes.

C, Kowal J, Darjan A, Meier W, Palivan CG.

Langmuir 2014 Oct $7 ; 30(39): 11660-9$.

02841p. Epub 2014 Sep 23. 
Annexe 2

Membres du comité de direction Fred Paccaud, UniSanté, Centre universitaire de méde-
cine générale et de santé publique; Faculté de biologie et de mérecine, Université de Lausanne, CH (président)

Stefania Boccia, Institute of Hygiene, Department of Public Health, Faculty of Medicine, Università Cattolica del Sacro Cuore of Rome, IT

Paolo Boffetta, Institute for Translational Medicine, Sinai, NY, USA

Alan Dangour, Centre on Climate Change and Planetary School of Hygiene \& Tropical Medicine, UK

Lynn Frewer, School of Natural and Environmental Sciences, University of Newcastle, UK

Dietrich Knorr, Institute of Food Technology and Food Chemistry, Berlin Institute of Technology, DE

Barbara Redlingshöfer, AgroParisTech, UMR SADAPT, INRA, Paris, FR

Greg Thoma, Ralph E. Martin Department of Chemical Engineering, University of Arkansas, USA

Bruce Traill, Agricultural \& Food Economics, University of Reading, UK

Marjory Hunt, FNS, Berne, $\mathrm{CH}$ (manager du programme)

Xavier Pilloud, VIRTÙ Public Affairs AG, Berne, $\mathrm{CH}$ (chargé du transfert de connaissances)

Stefanie Hellweg, Institute of Environmenta Engineering, Ecole polytechnique fédérale de Zurich, $\mathrm{CH}$ (déléguée du Conseil national de la recherche du FNS)

Michael Beer, Office fédéral de la santé publique, Berne, $\mathrm{CH}$ (représentant de l'Administration fédérale)

Markus Lötscher, Office fédéral de l'agriculture, Berne, $\mathrm{CH}$ (représentant de l'Administration fédérale)

Barbara Keller, CTI-KTI (désormais Innosuisse), Berne, $\mathrm{CH}$ (déléguée de la Commission pour la technologie et l'innovation) 


\section{Juin 2020}

Éditeur
Programme national de recherche PNR 69

Programme national de recherche PNR
Fonds national suisse
de la recherche scientifique (FNS)
Whilhainweg 3

Wildhainweg
Case postale

Gestion du projet
VIRTU Public Affairs AG

Mise en page/graphiques

Graphic Design

Photographies
Mélanie Rouiller 